\title{
An Experimental Investigation of the Impact of Random Spacing Errors on the Dynamic Transmission Error of Spur Gear Pairs
}

\section{THESIS}

Presented in Partial Fulfillment of the Requirements for Graduation with Honor's Research Distinction in the Department of Mechanical and Aerospace Engineering at The Ohio State University

\author{
By \\ Muhammad Nevin Anandika \\ Undergraduate Program in Mechanical Engineering
}

The Ohio State University

2018

Thesis Committee:

Dr. Ahmet Kahraman, Advisor

Dr. David Talbot 


\section{Copyrighted by}

Muhammad Nevin Anandika 


\begin{abstract}
Noise and vibration performance of a gear system is critical in any engineering industry, and especially the automotive industry. Excessive vibrational amplitudes originated by the excitations at the gear meshes propagate to the transmission housing to cause noticeable noise, while also increasing gear tooth stresses to degrade durability. As such, gear designers must generate designs that are nominally quiet with low-vibration amplitudes. This implies a gear pair fabricated exactly to the specifications of its blue print will be acceptable for its vibration behavior. Achieving this, however, is not sufficient. As the manufacturing of gears require them to be subject to bands of tolerances afforded by the manufacturing processes employed, the designers must be concerned about variations to the performance of their presumably quite baseline designs within these tolerance bands. This undergraduate research project aims at demonstrating how one type of manufacturing error, random tooth spacing errors, alter the vibratory behavior of a spur gear pair.
\end{abstract}

Two pairs of spur gears are tested for their dynamic transmission error performance. One gear pair with no tooth spacing errors form the baseline. The second gear pair contain an intentionally induced random sequence of spacing errors. The forced vibration responses of both gear pairs are compared within wide ranges of speed and torque. This comparison shows that there is a clear and significant impact of random spacing errors on spur gear dynamics, measurable through examination of their respective transmission error signatures. In the off-resonance regions of speed, vibration amplitudes of random error pair are higher than the no-error baseline spur gear pair. Meanwhile, at or near resonance 
peaks, the presence of random spacing errors tends to lower the peak amplitudes slightly as compared to the no-error baseline spur gear pair. The presence of random spacing errors introduces substantial harmonic content that are non-mesh harmonics. This results in a broadband frequency spectrum to an otherwise well-defined frequency spectrum with gearmesh order components, pointing to an additional concern of noise quality. 


\section{DEDICATION}

To my family, friends, and anyone who has supported me along the way. 


\section{ACKNOWLEDGEMENTS}

I would like to thank, first and foremost, Dr. Kahraman. None of this could have been possible without your advice, guidance, and support. The opportunity you have given me to learn and challenge myself in this space is greatly appreciated. Thank you to Dr. Talbot for serving on my defense committee, and always being willing to help and guide me throughout. Also to Michael Benatar, Michael Handschuh, Isaac Hong, and Jonny Harianto, for which your support and guidance on the project is invaluable. Thank you to the GearLab consortium, whose support and funding is what made this research possible. To my fellow students and co-workers in GearLab, thank you for the support and for creating an environment for which I can challenge myself and learn every day. Finally, to my family and friends for always being there throughout the good and the bad, and pushing me to challenge myself and grow each and every day. 
VITA

September $24^{\text {th }}, 1996 \ldots \ldots \ldots \ldots \ldots \ldots \ldots \ldots \ldots \ldots$ Born

Tuscaloosa, Alabama

June $2014 \ldots \ldots \ldots \ldots \ldots \ldots \ldots \ldots \ldots \ldots \ldots \ldots \ldots \ldots$ Dublin Scioto High School

Dublin, Ohio

February $2017 \ldots \ldots \ldots \ldots \ldots \ldots \ldots \ldots \ldots \ldots$ GearLab Research Associate

The Ohio State University

\section{FIELDS OF STUDY}

Major Field: Mechanical Engineering 


\section{TABLE OF CONTENTS}

Abstract............................................................................ i

Dedication.................................................................. ii

Acknowledgements.......................................................... iv

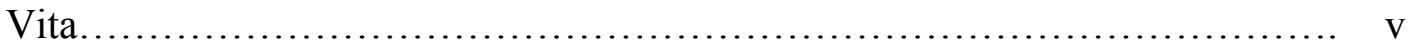

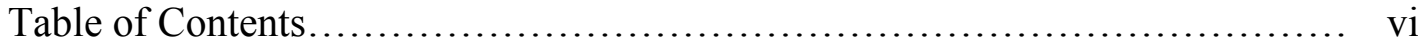

List of Tables............................................................. viii

List of Figures............................................................. xi

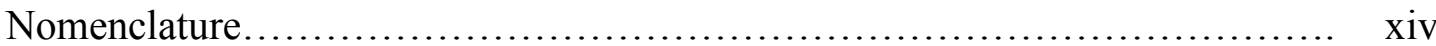

Chapter 1: Introduction................................................ 1

1.1 Background \& Motivation....................................... 1

1.2 Literature Review................................................ 3

1.2.1 Transmission Error Measurement....................... 3

1.2.2 The Effect of Spacing Errors........................... 5

1.3 Scope \& Objectives........................................... 9

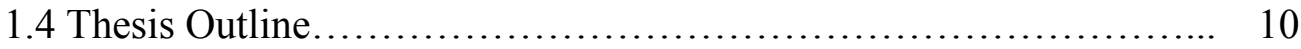

Chapter 2: Experimental Methodology ................................... 11

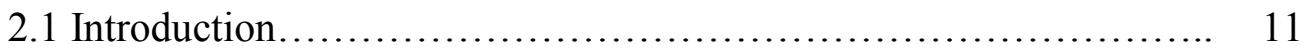

2.2 Experimental Setup.......................................... 11

2.3 Gear Specification \& Test Matrix .............................. 16

2.4 Measurement/DAQ Setup................................... 19 
2.5 Data Processing.

Chapter 3: Experimental Results \& Discussion............................. 34

3.1 Introduction.................................................... 34

3.2 Baseline Results............................................ 35

3.3 Random Error Gear Pair Results................................ 49

Chapter 4: Conclusion................................................ 63

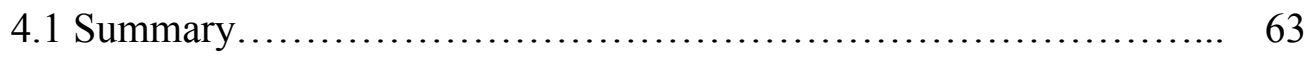

4.2 Major Conclusions............................................... 64

4.3 Recommendations for Future Work.............................. 65

References.................................................................. 66 


\section{LIST OF TABLES}

Table 2.1: Table 2.1: Gear parameters for the test gear set. All dimensions are

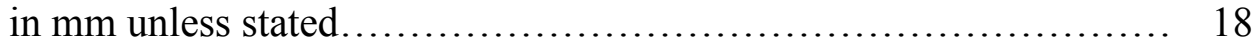

Table 2.2: Test matrix with spur gear test specimens. Measurements are derived from CMM trace values as seen in Figure $2.5 \ldots \ldots \ldots \ldots \ldots \ldots \ldots \ldots .21$

Table 2.3: $\quad$ Table 2.3: Test matrix utilized in this study........................ 24 


\section{LIST OF FIGURES}

Figure 2.1: $\quad$ Pictures of the test machine used in this study with and without the safety covers (adapted from Ref. [25])

Figure 2.2: Top view schematic of dynamic test machine (adapted from Ref.

$$
\text { [25]) }
$$

Figure 2.3: Mechanical loading of the power circulation loop using moment arm at the split coupling.

Figure 2.4: Split coupling located on the shaft where mechanical loading is employed.

Figure 2.5: $\quad$ Measured (a) profile and (b) lead traces of no-error spur gear $\# 2 \ldots$

Figure 2.6: $\quad$ Measured tooth-to-tooth spacing errors of test gears (a)\#1, (b) \#2 and (c) \#3.

Figure 2.7: (a) Schematic of uniaxial accelerometers mounted on the hubs of each gear, and (b) their implementation a test gear pair (adapted from Ref. [25])

Figure 2.8: Block diagram outlining the calculation of dynamic transmission error (adapted from reference [25])

Figure 2.9: Block diagram and schematic of the data acquisition system....... 
Figure 2.10: Slip ring orientations at the end of test gear shafts. The right shaft shows the hollow configuration through which the wires from the accelerometer(s) were passed, while the left shaft shows an example of the 10-channel slip ring utilized in this study (adapted

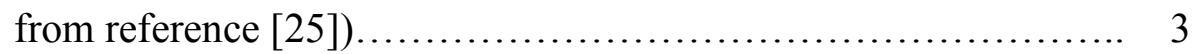

Figure 2.11: Schematic of slip ring wiring for both gear and pinion shafts, utilizing four uniaxial accelerometers (adapted from reference [25])

Figure 3.1: RMS DTE amplitudes, $A_{r m s}$, of the no-error gear pair at 100, 200, and $300 \mathrm{Nm}$ in (a) up-sweep and (b) down-sweep conditions........ 36

Figure 3.2: $\quad$ RMS DTE amplitudes, $A_{r m s}$, of the no error gear pair under up and down- sweep conditions at (a) $100 \mathrm{Nm}$, (b) $200 \mathrm{Nm}$, and (c) $300 \mathrm{Nm}$ 37

Figure 3.3: $\quad$ (a) $\ddot{\delta}(t)$ versus mesh cycles, (b) $\ddot{\delta}(t)$ versus $\dot{\delta}(t)$, and (c) FFT spectrum of the no-error spur gear pair at $100 \mathrm{Nm}, f_{\text {mesh }}=1083$ $\mathrm{Hz}$ (up-sweep) in between the first and second super-harmonic peak

Figure 3.4: $\quad$ (a) $\ddot{\delta}(t)$ versus mesh cycles, (b) $\ddot{\delta}(t)$ versus $\dot{\delta}(t)$, and (c) FFT spectrum of the no-error spur gear pair at $100 \mathrm{Nm}, f_{\text {mesh }}=1375$ $\mathrm{Hz}$ (up-sweep) at the first super-harmonic peak 
Figure 3.5: $\quad$ (a) $\ddot{\delta}(t)$ versus mesh cycles, (b) $\ddot{\delta}(t)$ versus $\dot{\delta}(t)$, and (c) FFT spectrum of the no-error spur gear pair at $100 \mathrm{Nm}, f_{\text {mesh }}=1792$ $\mathrm{Hz}$ (up-sweep) in between the first super-harmonic and primary resonance peak ...............................................

Figure 3.6: $\quad$ (a) $\ddot{\delta}(t)$ versus mesh cycles, (b) $\ddot{\delta}(t)$ versus $\dot{\delta}(t)$, and (c) FFT spectrum of the no-error spur gear pair at $100 \mathrm{Nm}, f_{\text {mesh }}=2292$ $\mathrm{Hz}$ (up-sweep) at the lower branch of the jump discontinuity near resonance.

Figure 3.7: $\quad$ (a) $\ddot{\delta}(t)$ versus mesh cycles, (b) $\ddot{\delta}(t)$ versus $\dot{\delta}(t)$, and (c) FFT spectrum of the no-error spur gear pair at $100 \mathrm{Nm}, f_{\text {mesh }}=2282$ $\mathrm{Hz}$ (down-sweep) at the upper branch of the jump discontinuity near resonance

Figure 3.8: $\quad$ (a) $\ddot{\delta}(t)$ versus mesh cycles, (b) $\ddot{\delta}(t)$ versus $\dot{\delta}(t)$, and (c) FFT spectrum of the no-error spur gear pair at $100 \mathrm{Nm}, f_{\text {mesh }}=2450$ $\mathrm{Hz}$ (up-sweep) after the jump discontinuity near resonance.

Figure 3.9: Waterfall plot of $\delta(t)$ for the no-error spur gear pair at $100 \mathrm{Nm}$ in the down-sweep condition.

Figure 3.10: Waterfall plot of $\delta(t)$ for the no-error spur gear pair at $300 \mathrm{Nm}$ in the down-sweep condition.

Figure 3.11: RMS DTE amplitudes, $A_{r m s}$, of the random-error gear pair at 100, 200, and $300 \mathrm{Nm}$ in (a) up-sweep and (b) down-sweep conditions.. 50 
Figure 3.12: $\quad$ RMS DTE amplitudes, $A_{r m s}$, of the random-error gear pair under up and down- sweep conditions at (a) $100 \mathrm{Nm}$, (b) $200 \mathrm{Nm}$, and

(c) $300 \mathrm{Nm}$.

Figure 3.13: Comparison of the forces response curves (both up and downsweep included) of the no-error and random-error gear pairs at (a) $100 \mathrm{Nm}$, (b) $200 \mathrm{Nm}$ and (c) $300 \mathrm{Nm}$.

Figure 3.14: (a) $\ddot{\delta}(t)$ versus mesh cycles, (b) $\ddot{\delta}(t)$ versus $\dot{\delta}(t)$, and (c) FFT spectrum of the random-error spur gear pair at $100 \mathrm{Nm}, f_{\text {mesh }}=$ $1021 \mathrm{~Hz}$ (up-sweep) in between the first and second superharmonic peak.........................................

Figure 3.15: (a) $\ddot{\delta}(t)$ versus mesh cycles, (b) $\ddot{\delta}(t)$ versus $\dot{\delta}(t)$, and (c) FFT spectrum of the random-error spur gear pair at $100 \mathrm{Nm}, f_{\text {mesh }}=$ $1271 \mathrm{~Hz}$ (up-sweep) at the first super-harmonic peak

Figure 3.16: (a) $\ddot{\delta}(t)$ versus mesh cycles, (b) $\ddot{\delta}(t)$ versus $\dot{\delta}(t)$, and (c) FFT spectrum of the random-error spur gear pair at $100 \mathrm{Nm}, f_{m e s h}=$ $1667 \mathrm{~Hz}$ (up-sweep) between the first super-harmonic and primary resonance peak......

Figure 3.17: (a) $\ddot{\delta}(t)$ versus mesh cycles, (b) $\ddot{\delta}(t)$ versus $\dot{\delta}(t)$, and (c) FFT spectrum of the random-error spur gear pair at $100 \mathrm{Nm}, f_{\text {mesh }}=$ $2146 \mathrm{~Hz}$ (up-sweep) prior to the first jump near resonance. 
Figure 3.18: (a) $\ddot{\delta}(t)$ versus mesh cycles, (b) $\ddot{\delta}(t)$ versus $\dot{\delta}(t)$, and (c) FFT spectrum of the random-error spur gear pair at $100 \mathrm{Nm}, f_{\text {mesh }}=$ $2229 \mathrm{~Hz}$ (up-sweep) directly after the first jump approaching

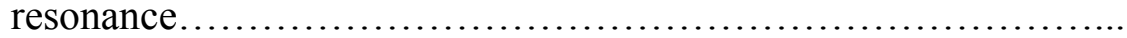

Figure 3.19: (a) $\ddot{\delta}(t)$ versus mesh cycles, (b) $\ddot{\delta}(t)$ versus $\dot{\delta}(t)$, and (c) FFT spectrum of the random-error spur gear pair at $100 \mathrm{Nm}, f_{\text {mesh }}=$ $2438 \mathrm{~Hz}$ (up-sweep) after the second jump, closest to resonance....

Figure 3.20: Waterfall plot of $\delta(t)$ for the random-error spur gear pair at 100 $\mathrm{Nm}$ in the down-sweep condition............................ 61

Figure 3.21: Waterfall plot of $\delta(t)$ for the random-error spur gear pair at 300 $\mathrm{Nm}$ in the down-sweep condition............................ 62 


\section{NOMENCLATURE}

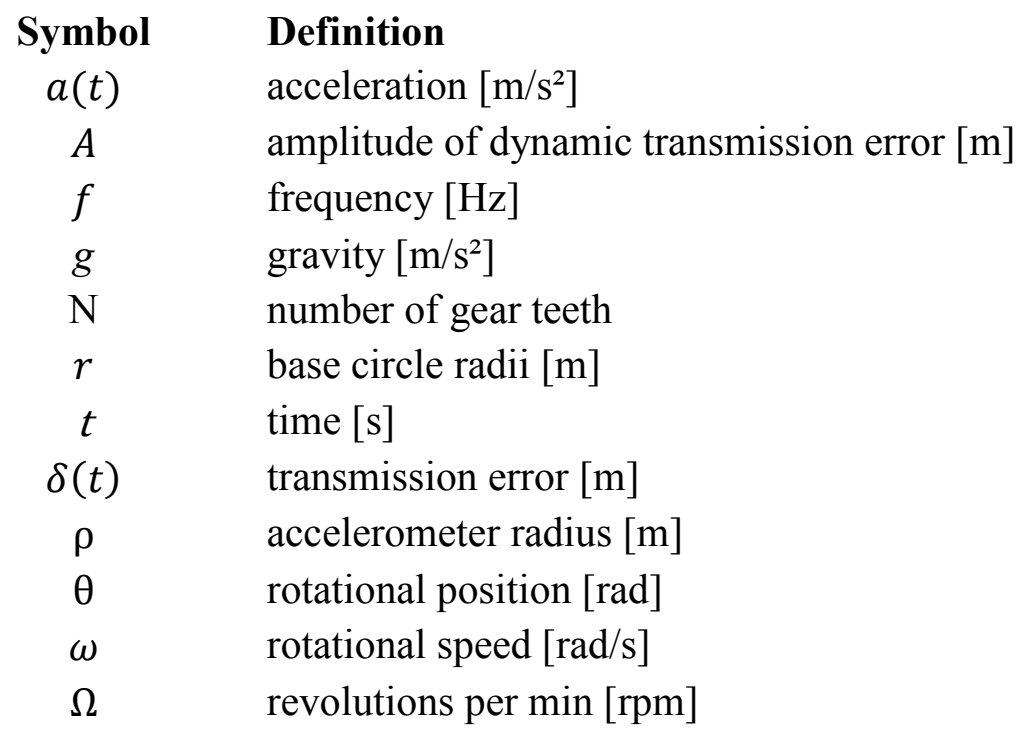

\section{Subscripts}

$\begin{array}{cl}g & \text { gear } \\ \text { mesh } & \text { mesh } \\ n & \text { harmonic (as in } n^{\text {th }} \text { harmonic from 1 to 5) } \\ n a t & \text { natural (as in natural frequency) } \\ p & \text { pinion } \\ r m s & \text { root mean squared } \\ T & \text { tangential acceleration }\end{array}$

\section{Superscripts}

second derivative

first derivative 


\section{CHAPTER 1}

\section{INTRODUCTION}

\subsection{Background \& Motivation}

The consideration of noise and vibration harshness in engineering design is critical in any industry. Gear designers put forward significant effort to ensure NVH (noise, vibration and harshness) behavior of their gears are acceptable. If not designed properly, vibrational amplitudes from the gear meshes of a gear pair can accumulate and excite systems leading to noticeable noise, increases stresses, decreased durability, and possible failure of the system. Due to this concern, gear designers must generate designs that are nominally quiet with low-vibration amplitudes. This implies a gear pair fabricated exactly to the specification of its blue print will be acceptable for its NVH behavior. Achieving this, however, is not sufficient. As manufacturing of gears require them to be subject to bands of tolerances afforded by the manufacturing processes employed, the designers must be concerned about variations to the performance of their presumably quite baseline designs within these tolerance bands. This undergraduate research project aims at demonstrating how one type of manufacturing error, random tooth spacing errors, alter the vibratory behavior of a spur gear pair.

One rather trivial solution to this problem is to fabricate gears to higher quality classes where manufacturing error tolerance bands are narrowed. While this might work 
for certain industries such as aerospace systems, it is not desirable for high-volume applications such as automotive transmissions because of the high costs that comes with increased quality. As such, it is important to understand the consequences of manufacturing errors on gear $\mathrm{NVH}$ behavior such that gear designers can find a balance among quality, cost, manufacturability and the NVH performance of their designs.

In order to understand the relationship between errors and gear vibration, one must study the vibration excitations generated at the gear meshes. A common gear vibrations (and hence noise) metric is the motion transmission error (TE). Defined in a torsional sense as the deviation in the actual position of a driven gear and the position of the gear if it were perfectly conjugate, larger motion TE values tend to correlate to higher noise and increased vibrational amplitudes of a system. Numerous studies have employed TE as a metric to understand the relationship between certain manufacturing errors and the resulting noise and vibrational behavior of the gear system.

One such manufacturing error of interest is tooth spacing or indexing error, defined as the difference in the actual position and the nominal position of a gear tooth along the pitch of a gear. A gear with spacing errors might experience premature or over-extended tooth contacts. This leads to sudden changes in the meshing action, in the process, adversely affecting the vibration response of the gear pair.

Previous literature as it will be presented in the following section often was concerned with adverse effects of spacing errors on dynamic tooth forces and gear durability. Increased dynamic stress factors due to spacing errors can be detrimental to the long-cycle performance of the gear pair. This study aims at experimentally demonstrating 
what such randomly sequenced tooth spacing errors do to the motion transmission error of a spur gear pair under high-speed dynamic conditions. As the primary future focus of the research is on the effect of such random spacing errors on helical gears, a much more commonly used gear in industry, this undergraduate research thesis on spur gears is intended to serve as a feasibility study for a graduate research project on helical gears.

\subsection{Literature Review}

\subsubsection{Transmission Error Measurement}

Geometrical imperfections have been considered as early as the 1930s with works by Walker [1]. Methods on how to measure and study the effect of these imperfections on gear performance was sought soon after these initial works. Harris [2] laid out a substantial portion of theoretical work, which pursued measurement methods of gear vibrations from geometrical imperfections. His initial theoretical approach for the study of amplitudes of vibrations of spur gears were by means of studying damping effects, but damping was found to be insufficient to predict the dynamic effects of spur gears. Harris then proposed the idea of motion transmission error (TE), defined as the difference in the actual position of a driven gear and the position of the gear if it were perfectly conjugate, as a method to measure amplitudes of vibration. This was tremendous in outlaying the superficial understanding of motion transmission error as an idea. Welbourn [3] conducted a fundamental survey of existing research on gear noise and was critical in establishing motion TE as a widely accepted parameter to study vibrations in gear systems, as well as linking motion TE to gear noise. 
With motion TE established as a noise metric, theoretical models such as those by Mark [4], and Kohler and Regan [5] using motion TE were pursued. Mark expanded on Harris' initial idea of motion TE and provided a theory for prediction of vibration excitations of gear systems with manufacturing errors (such as profile and pitch errors) using transmission error and Fourier series transfer functions. Mark also looked at different design parameters on the effect of TE excitation. On the other hand, Kohler and Regan investigated the effect of profile errors on gear transmission error. Over the next few decades, substantial experimental work on gear vibrational behavior and transmission error was conducted.

An earlier experimental study by Munro [6] used single and dual flank composite measurement methods, which considered meshing of a single tooth against another single tooth and then calculated the TE for each tooth mesh. Munro used this to study the effect of geometrical (profile and pitch) errors on the motion TE of gears. As various measurement methods of TE developed, it was clear certain methods were better established then others. Munro [7] reviewed these various transmission error methodologies, reviewing the limitations, pros, and cons of the various experimental methods. Currently, there are two well established methods to study motion TE, depending on the operating speed condition of the system. At low speed operating conditions, motion $\mathrm{TE}$ is considered static transmission error (STE), and modern-day research often implements the use of rotary encoders to measure this STE. At high speed operating conditions, motion TE is considered dynamic transmission error (DTE), and modern-day research often implements an accelerometer-based measurement system to measure this DTE. 
Smith [8] investigated the accuracy of gear transmission error measurements using the rotary encoders as an experimental method. His work helped to establish rotary encoders as an ideal experimental method for TE at low speeds. Kurokawa [9] studied gears under load with high precision static transmission error measurements through rotary encoders. Milliren [10] implemented two rotary encoders on parallel shafts to study the effect of various manufacturing errors on the transmission error of spur gears at low speed operating conditions. Handschuh et al. [11] also implemented rotary encoders to study the impact of random pitch or spacing errors on the static transmission error of spur gears. Regarding studies of gears at high operating speed conditions, Blankenship and Houser [12] showed that accelerometers are ideal for measuring TE in dynamic, high operating speed conditions. Kahraman and Blankenship implemented an accelerometer-based measurement system to study the effect of involute contact ratio [13] and involute tip relief [14] on spur gear dynamics and dynamic TE. This specific accelerometer-based measurement system utilized two diametrically opposed accelerometers per gear to cancel the effects of gravity. Kang and Kahraman [15] implemented tri-axial accelerometers to measure motions outside of just rotational vibrations. With rotary encoders to study static TE and accelerometers to study dynamic TE, these two experimental methods paved the way for researchers to study the effects of various manufacturing errors on gear vibrations and noise.

\subsubsection{The Effect of Spacing Errors}

Spacing error, also referred to as indexing or pitch error, is a circumferential position error along the pitch of a gear of one gear tooth flank with respect to an adjacent gear tooth flank. The presence of spacing errors on a gear leads to overextended or 
premature tooth contacts outside of the intended plane of action, which inherently contributes to motion TE $[3,16-19]$. Due to the impact of tooth spacing errors on the TE of gear systems, an effort in research exists to study this error.

Harris [2] showed that geometrical errors, such as spacing or pitch error, can impact more than the one mesh cycle with the error and lead to resultant transient vibrations in the mesh cycles proceeding the mesh cycle with the error. Kohler and Regan [5] found that profile errors, which relate to the presence of spacing errors, introduce additional frequency components to the frequency spectrum outside of just the tooth contact harmonics. This finding supports a similar conclusion made by Welbourn [3] which stated that pitch errors add shaft frequencies (or additional frequency components) and their multiples to the frequency spectrum, outside of the tooth contact or gear mesh frequencies and their harmonics. Hayashi and Hayashi [20] who evaluated the impact of nine types of tooth profile error on motion TE, including pitch error, concluded that the vibrations of TE are dependent on the magnitude of error, contact ratio, and the operating speed of gears. Umezawa et al. [21] and Umezawa and Soto [22] came to a similar conclusion on the effect of accumulative pitch errors affecting TE. They showed the dependence between contact ratio and operating speed to something they called "acceleration value," an equivalent to TE. They also showed that an increase in contact ratio reduces the impact of pitch errors on the resultant torsional vibrations. Bonori and Pellicano [23] found that manufacturing errors, such as pitch errors, lead to magnified amplitudes of vibrations. They also concluded that profile errors within the same AGMA quality class rating can cause variations in vibratory activity. 
Modern-day research concerning the impact of spacing or indexing errors on the static TE of gears operating at low speeds include both gear dynamics and gear stresses. Milliren [10] studied the impact of various errors such as indexing error on the static TE and root stresses of spur gears. He found that the presence of indexing errors clearly influences TE, with harmonic orders of TE increasing significantly to cause a slightly more broadband frequency spectrum. Relating to the impact on root stresses, Milliren [10] found that a tooth with negative spacing error is relieved of most of its load carrying duty, but the preceding tooth stays in the mesh longer than usual and causes higher root stresses in this preceding tooth. In addition, the tooth following the negative indexing error enters the gear mesh earlier, resulting in a longer duration of loading. It was also found that a larger amplitude in error can lead to an impact of surrounding gear teeth.

Handschuh et al. [11] expanded this study to include the effect of discrete and randomly spaced indexing errors on the static transmission error and root stresses of spur gears. This presence of errors throughout the whole gear affects the amplitudes of nearly all shaft orders in the TE frequency spectrum, again to a broadband frequency spectrum, which makes the gear more susceptible to being excited through resonance at more frequencies. They also concluded that positive indexing errors are worse for driving root stresses, and negative errors worse for driven gear root stresses.

As an understanding of the effect of spacing errors on gear dynamics and stresses at low operating speed conditions was now established, research on the errors at high speed operating conditions was pursued. Talbot et al. [24] studied the impact of indexing errors in this dynamic range of operating speeds by characterizing the dynamic factors of root stresses of spur gears. Talbot found a clear impact of indexing errors on the maximum 
stress values, time durations in mesh, and stress signal shape. Their conclusions matched that of Milliren [10] and Handschuh [11], which found negative indexing errors reduced the maximum stresses and time in mesh, while for the proceeding teeth, maximum stresses were increased, which can sometimes be seen present for multiple teeth after the mesh. They found that the dynamic operating conditions led to greater than expected stresses. Talbot et al. [24] also provided a dynamic load distribution model, which correlated to the experiments well.

Anichowski [25] and Anichowski et al. [26] investigated the impact of isolated indexing errors on the dynamic transmission error of spur gears. Anichowski found that single indexing errors introduced some non-mesh order components that are not the gear mesh orders to the frequency spectrum, but overall, the dynamic TE behavior existed along the gear mesh orders. He found that the impact of a single indexing error did not disturb the non-linear behavior of tooth contact loss observed at resonant frequencies of the spur gear pair. The transient acceleration behavior induced by the presence of the indexing error was observed to increase acceleration amplitudes, but these vibrations dissipated prior to the start of the new rotational period, maintaining the periodicity of the vibration signal over multiple rotational periods. Overall though, they found that the presence of tooth indexing errors introduced non-mesh harmonic content, which points to a concern for noise quality in gear systems.

Despite the current state of research progress looking into the impact of spacing errors on gear dynamics, there remains a lack of research considering realistic cases of spacing error, where errors are randomly sequenced throughout the whole gear. This study 
aims at filling in this gap in research by considering the impact of randomly sequenced spacing errors on the dynamic transmission error of spur gears.

\subsection{Scope \& Objectives}

This study acts as an extension of an earlier study by Anichowski et al. [26] who investigated the influences of isolated spacing errors on the loaded, dynamic response of a spur gear pair by characterizing the dynamic transmission error (TE). With the lack of results on the effect of realistic or randomly spaced spacing errors on the dynamic response of a spur gear pair, this study will experimentally determine the impact of realistic (random) spacing error sequences on the loaded dynamic TE of spur gear pairs. This will expand the experimental database of studies on spacing errors to cover the realistic gear conditions. The same dynamics machine and accelerometer measurement system utilized by Kang and Kahraman [15] will be employed in this study to measure the transient rotational vibrations caused by the random tooth indexing error matchings. These measurements will be compared to the dynamic TE response of a gear with negligible error, to act as a baseline test. The following objectives of this study are as follows:

- Perform steady-state and transient spur gear dynamics experiments to investigate the impact of a random spacing error sequence on the dynamic TE within a range of torque.

- Compare the response of the gear pair having random spacing errors to that of negligible error to highlight the contributions of these errors to the forced response. 
This study will investigate the dynamics of unity-ratio spur gear pairs. In addition, the only type of error considered in this study is the effect of the random spacing error. Utilizing the methodology proposed in this study, one can investigate the effect of other manufacturing errors on the loaded, dynamic TE response of a spur gear pair. A similar methodology with a modified accelerometer can be employed to investigate manufacturing errors on helical gears. As the primary future focus of research is on helical gear behavior under such randomly sequenced spacing errors, this study acts as a feasibility study.

\subsection{Thesis Outline}

Chapter 2 introduces the experimental test set-up and methodology used to perform the set of experiments. It provides a detailed description of the gear dynamics test machine utilized to perform the experiment, with the operating conditions for the various tests. Gear design specifications and a test matrix is provided. A brief explanation of the measurement and data acquisition (DAQ) systems is provided, which follows with the data analysis methodology. Chapter 3 provides a set of results from both steady-state and transient tests. Results of the no-error baseline test are provided in detail first, followed by an overview of the randomly sequenced spacing error gear set results, emphasizing any differences between the random-error test results and the no-error baseline test results. Chapter 4 provides an overall summary of the research with any major conclusions found that characterize the dynamic behavior of gears with manufacturing spacing errors. Also, recommendations and plans for future research work related to this topic are provided. 


\section{CHAPTER 2}

\section{EXPERIMENTAL METHODOLOGY}

\subsection{Introduction}

This chapter describes the methodology employed to perform a set of experiments towards achieving the research objectives. The test machine setup, including its key features will be introduced first, along with its operating conditions for the steady-state and transient gear experiments. Gear design specifications and the test matrix will be introduced. A brief explanation of the measurement and data acquisition systems will be provided, as they have been described in an earlier study [15]. The data analysis methodology to convert the raw experimental data into the relevant vibration metrics, achieved by dedicated LabVIEW and MATLAB programs, will be described.

\subsection{Experimental Setup}

The test machine employed in this study is a back-to-back, power-circulation type test machine as shown in Figure 2.1. The same test machine was used in earlier gear dynamics experiments in order to investigate various vibration characteristics of spur [14, 

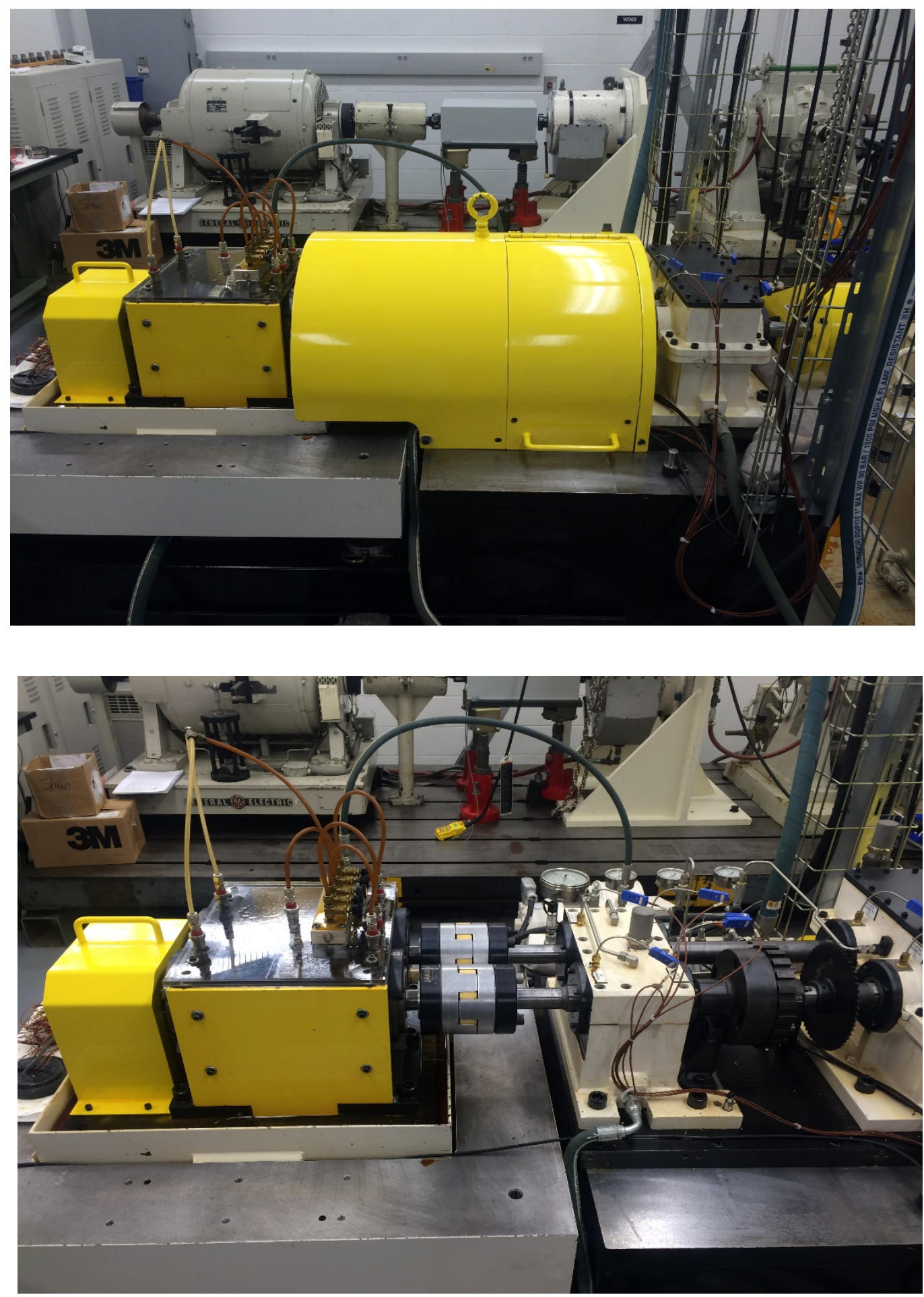

Figure 2.1: Pictures of the test machine used in this study with and without the safety covers (adapted from Ref. [25]). 
26-29], helical [30], and double helical [15] gear pairs. The most recent documented use of the machine studied the effect of isolated indexing errors on the dynamic transmission error of a spur gear pair [25]. A detailed explanation of the features and capabilities of the test machine can be found in the aforementioned studies. The details given in this section on the test machine will highlight only the relevant aspects to this experimental study.

The most important design feature of the test machine shown in Figure 2.1 is its ability to isolate the vibrations observed on the test gear set from the rest of the machine. This is possible through long compliant shafts connecting the test gearbox from the reaction gearbox. Compliant elastomeric couplings with low stiffness on the shafts between the gearboxes further isolate these vibrations from one gearbox to the other. A schematic of the test machine is shown in Figure 2.2 to label its key components.

A constant torque is applied to the power circulation loop by mechanically loading a split coupling at the driving shaft, as seen in Figure 2.3 and 2.4. This mechanical loading is implemented using a moment arm and different sets of weights to apply different amounts of torque to the back-to-back power circulation loop. A small DC motor connects to the driving shaft of the test machine via pulley drive. The motor itself is controlled by an Allen Bradley PLC, which monitors the real time speed of the shafts and the lubrication systems of the machine. Sets of steady-state and transient tests are performed for the purposes of this study. For the steady-state tests, user determined upper and lower speed limits, speed increment values, ramp rates $\left(\mathrm{rpm} / \mathrm{s}^{2}\right)$, and up-sweep or down-sweep directions are defined in the programmable PLC. For the transient tests, upper and lower speed limits, dwell times, and ramp rates are set. Both sets of tests are performed between 


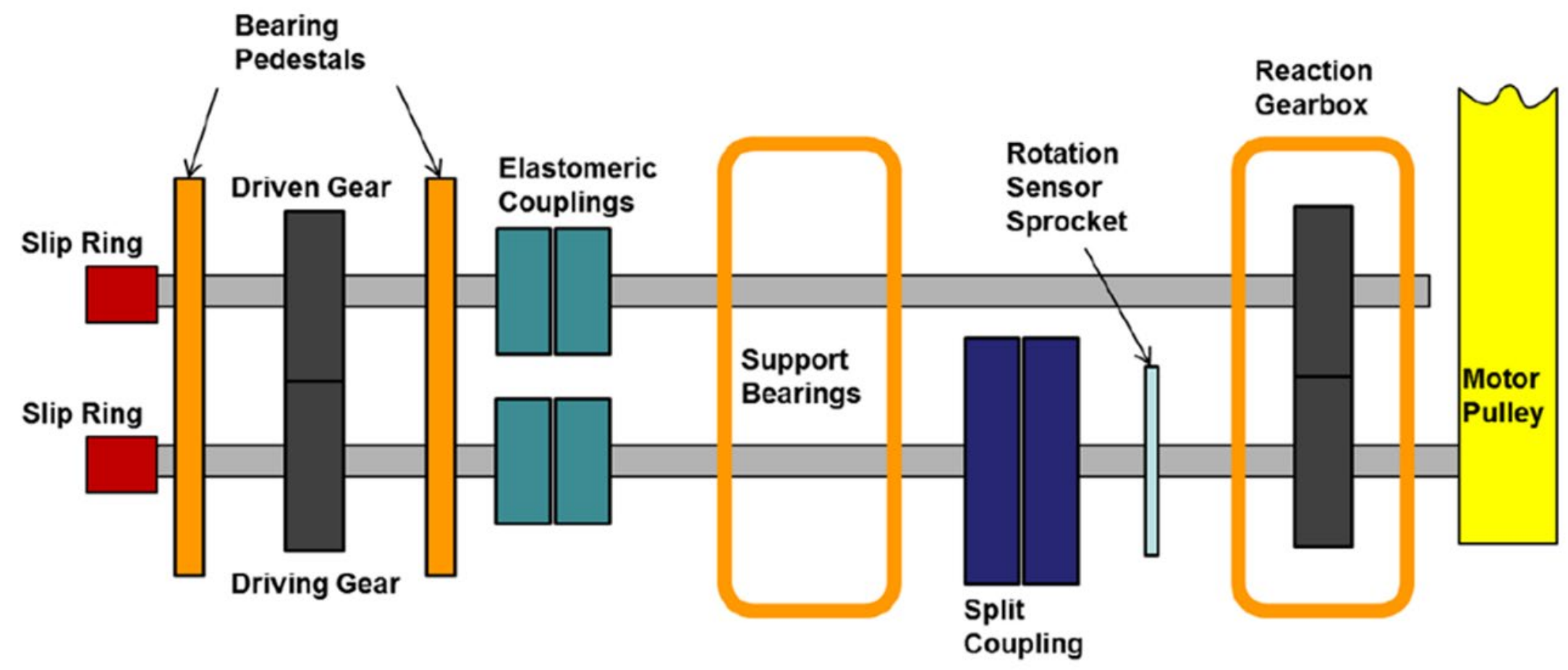

Figure 2.2: Top view schematic of dynamic test machine (adapted from Ref. [25]). 


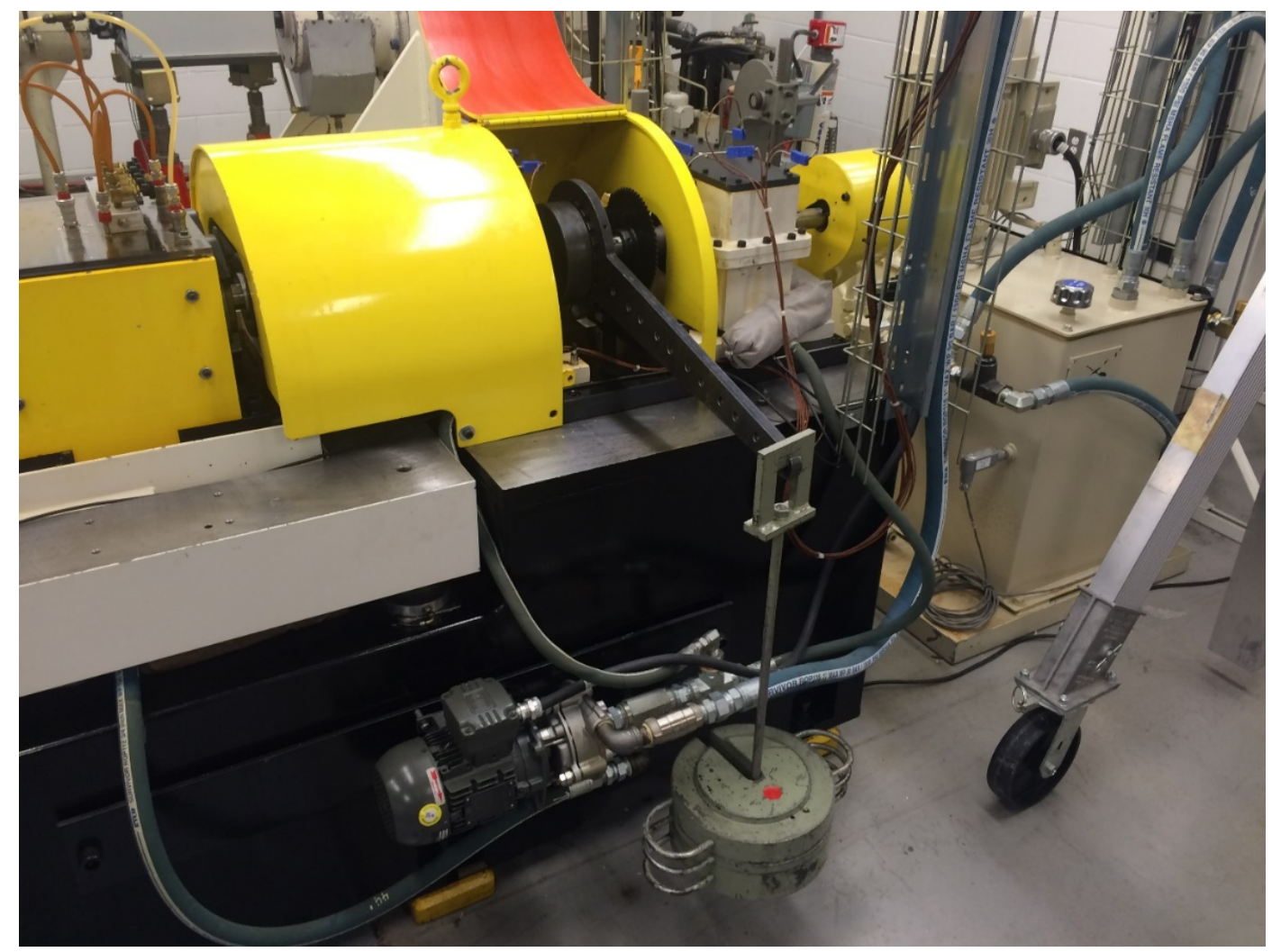

Figure 2.3: Mechanical loading of the power circulation loop using moment arm at the split coupling.

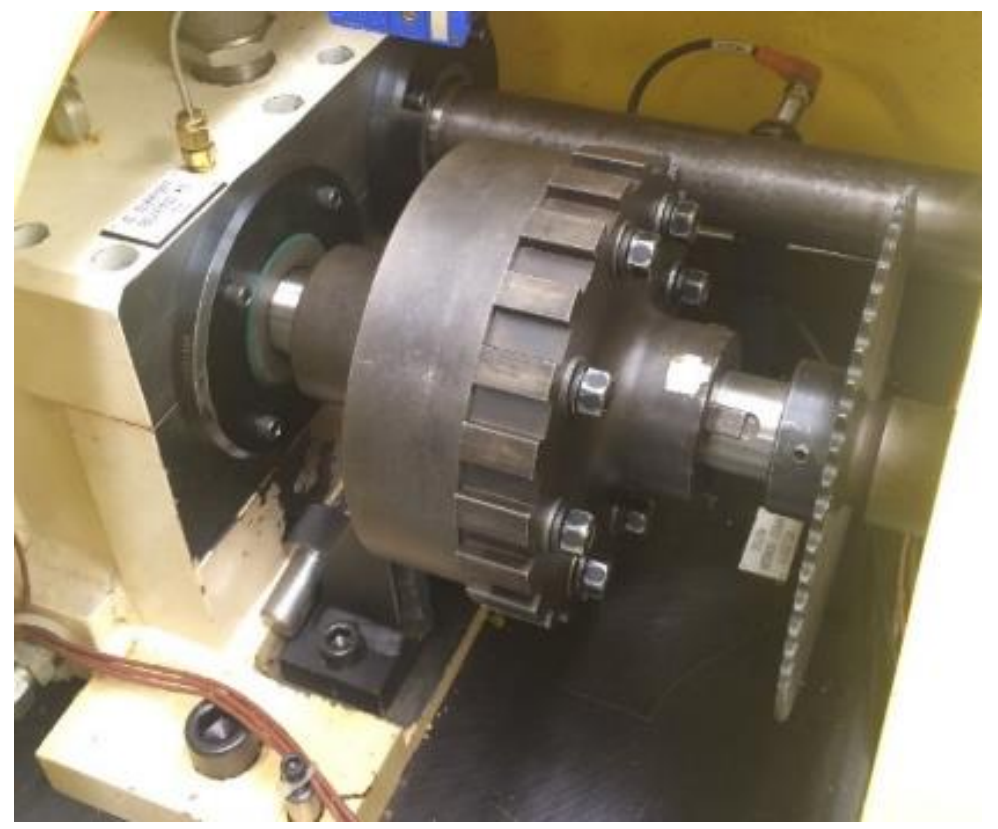

Figure 2.4: Split coupling located on the shaft where mechanical loading is employed. 
ranges of 500 to $4200 \mathrm{rpm}$. Previous studies have shown this range of speeds is capable of capturing the five harmonics in the gear mesh harmonic frequency spectrum of the gear pair [25]. The steady state test will increase in increments of $25 \mathrm{rpm}$ in the range mentioned, while the down-sweep will do the same, except upper and lower limits are offset by $13 \mathrm{rpm}$ to capture the midpoints of the up-sweep. In either direction, ramp rates are set at 0.50 $\mathrm{rpm} / \mathrm{s}^{2}$. The transient test will begin in the up-sweep and operate within the same range of speeds with the same ramp rate of $0.50 \mathrm{rpm} / \mathrm{s}^{2}$. Once at the upper limit, the test will dwell for 30 seconds before proceeding to the down-sweep at the same ramp rate.

\subsection{Gear Specification \& Test Matrix}

The design of the test gears employed in this study follows those of previous experimental studies looking into similar gear dynamic behavior [14-15, 25, 27-29]. The test gear set used is a unity-ratio spur gear pair of 50 teeth per gear. Table 2.1 lists common design parameters of the test gears and Figure 2.5 shows an example set of profile and lead traces measured by using a gear CMM. All gear sets employed are operated at a center distance of $150 \mathrm{~mm}$. It is also notable that all gears have no profile modifications (i.e. intended profiles are involute shapes). These gears were initially manufactured for a study by Handschuh et al [11], and later employed in studies by Talbot et al [24] and Anichowski et al [26]. The indexing errors are put into the gears by first fabricating a gear, given the designed gear parameters, with negligible indexing error. Additional material is then removed off the contact surfaces of individual teeth to induce a predetermined indexing error sequence. 
Table 2.1: Gear parameters for the test gear set. All dimensions are in mm unless stated.

\begin{tabular}{ll}
\hline Parameter [unit] & Value \\
\hline Number of Teeth & 50 \\
Normal Module & 3.00 \\
Pressure Angle [deg] & 20.0 \\
Pitch Diameter & 150.0 \\
Base Diameter & 140.95 \\
Major Diameter & 156.00 \\
Minor Diameter & 140.68 \\
Circular Tooth Thickness & 4.64 \\
Active Fact Width & 20.0 \\
Tip Relief Magnitude & 0.00 \\
Blank Width & 32.7 \\
Active Face Width & 20.0 \\
\hline
\end{tabular}


(a)

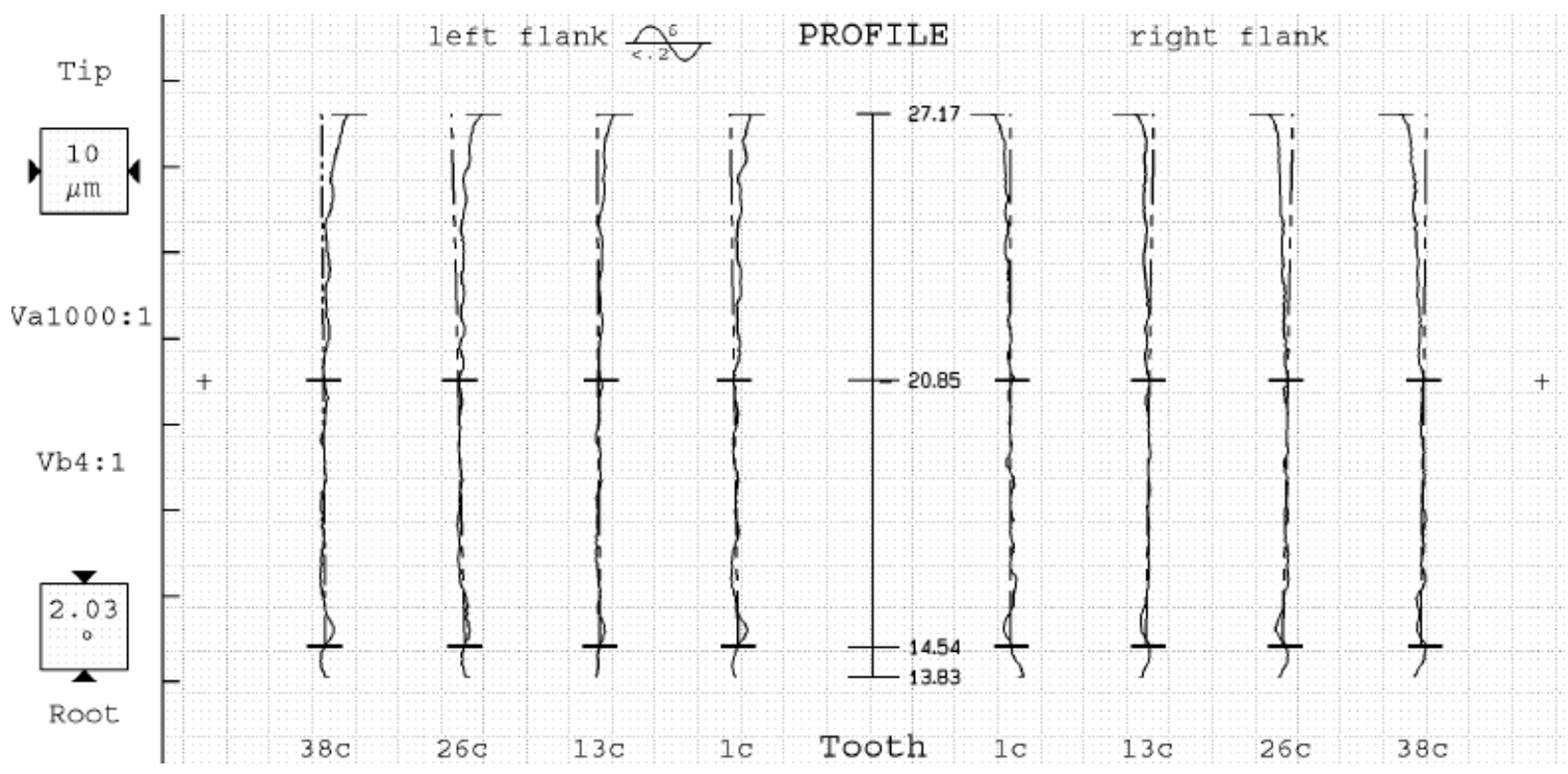

(b)

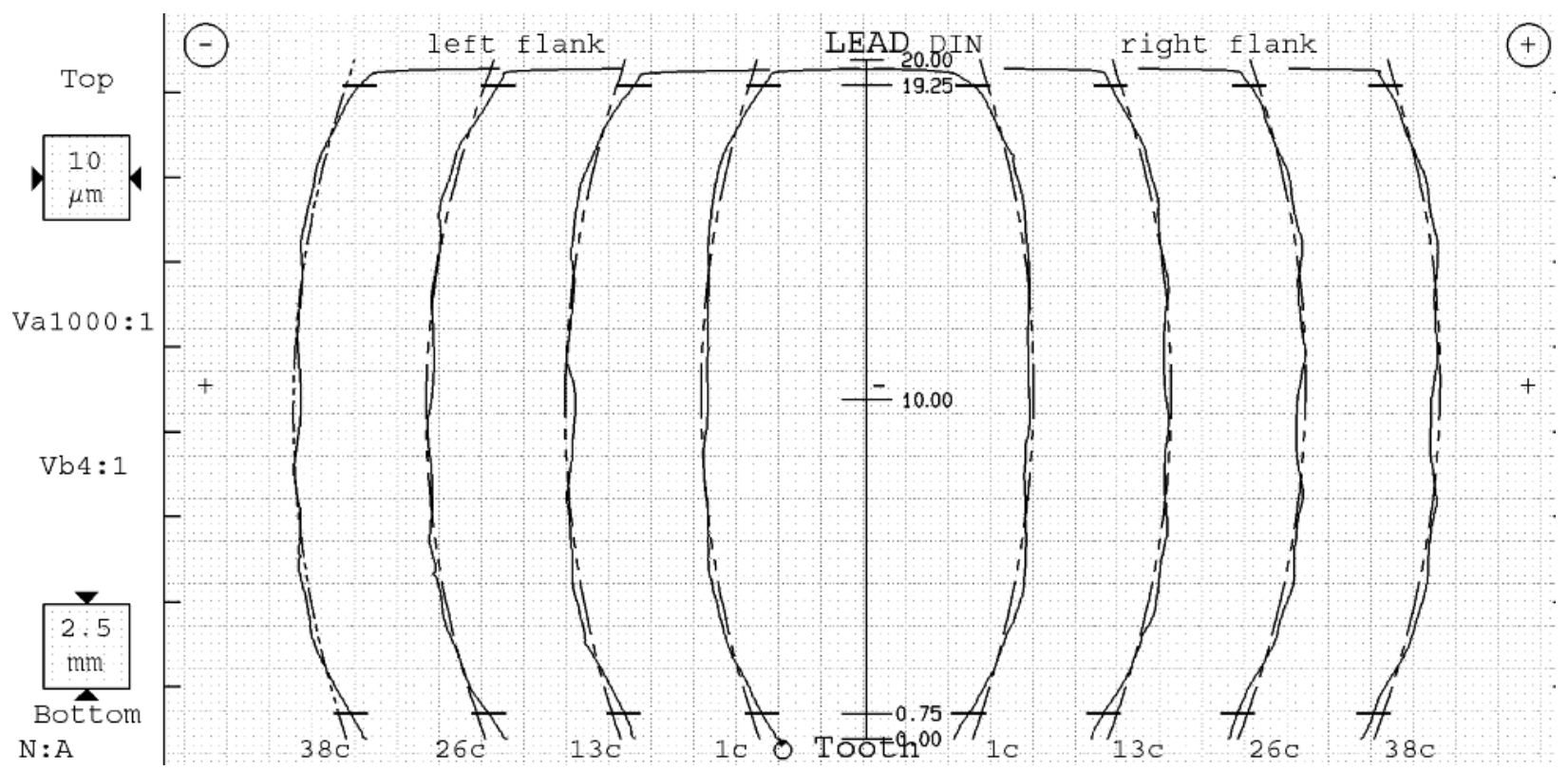

Figure 2.5: Measured (a) profile and (b) lead traces of no-error spur gear \#2 
Three separate gears were used in the experimental test matrix of Table 2.2. Two of these test gears had negligible tooth-to-tooth spacing error throughout the whole pitch of the gears, while the third gear had a random sequence of tooth-to-tooth spacing errors within a band of $20 \mu \mathrm{m}$. Measured tooth-to-tooth spacing error sequences of all three test gears are shown in Figure 2.6. The pairing of gear $\# 1$ and $\# 2$, both of negligible error, is intended to act as a baseline test while the pairing of gear pair \#1 and \#3 represents a test gear pair with random indexing errors. The set of tests employed in this study are seen in Table 2.3. By comparing the results and dynamic behavior observed in the gear pair with random indexing errors to the results of the baseline test, one can sufficiently highlight the contributions these indexing errors have on the forced response of a spur gear pair.

Each gear pair (pair \#1-\#2, and pair \#1-\#3) will be tested at three torque levels of 100, 200, and $300 \mathrm{Nm}$. The two distinct steady-state and transient tests will be performed, both within the speed range of $\Omega=500$ to $4200 \mathrm{rpm}$. Considering the presence of $\mathrm{N}=50$ teeth on each gear pair, the mesh frequency range of the test gear pair for both sets of tests

will be completed at $f_{\text {mesh }}=\frac{N \cdot \Omega}{60}=417-3500 \mathrm{~Hz}$. The same speed range was shown earlier to contain primary and super-harmonic resonance peaks of this gear pair [14-15, 25, 27-29].

\subsection{Measurement/DAQ Setup}

The accelerometer-based measurement system used here was originally developed by Kang and Kahraman [15] to capture the vibrations seen in the test gear pair. This measurement system employs two diametrically opposed uniaxial accelerometers mounted on the hubs of each gear at a radius of $\rho$ measuring in the rotational direction, as seen in 
Table 2.2: Test matrix with spur gear test specimens. Measurements are derived from CMM trace values as seen in Figure 2.5.

\begin{tabular}{ccccc}
\hline Gear Number & $\begin{array}{c}\text { Indexing Error } \\
\text { Type }\end{array}$ & $\begin{array}{c}\text { Average Tooth- } \\
\text { Tooth Spacing } \\
\text { error }[\mu \mathrm{m}]\end{array}$ & $\begin{array}{c}\text { Standard Deviation } \\
\text { of Errors } \\
{[\mu \mathrm{m}]}\end{array}$ \\
\#1 (Driving) & None & 0.9 & $\begin{array}{c}\text { Relative Tooth-to-Tooth Spacing Error Profile } \\
\text { along the pitch of the gear }\end{array}$ \\
\#2 (Driven) & None & 0.5 & 0.6 \\
\#3 (Driven) & Random & 4.7 & 6.2 \\
\hline
\end{tabular}


(a)

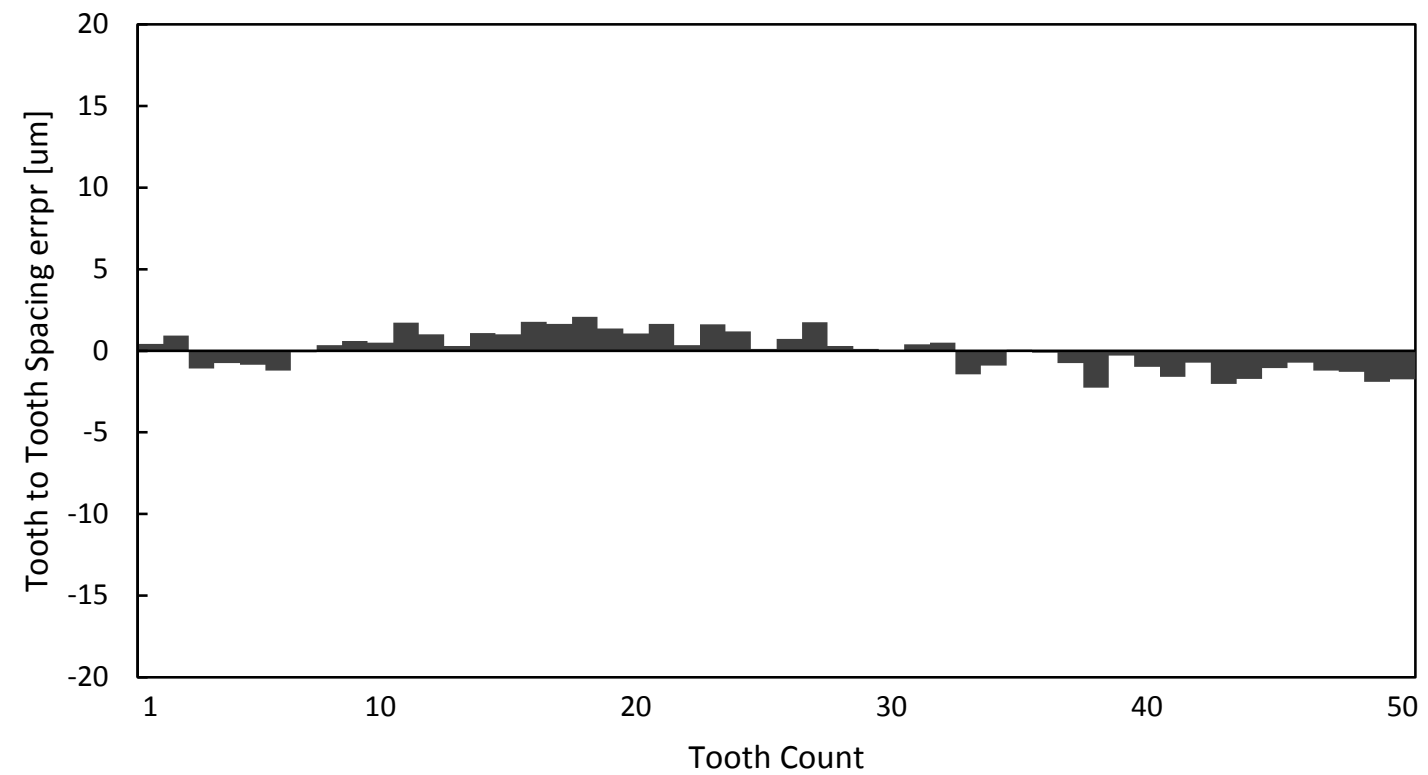

(b)

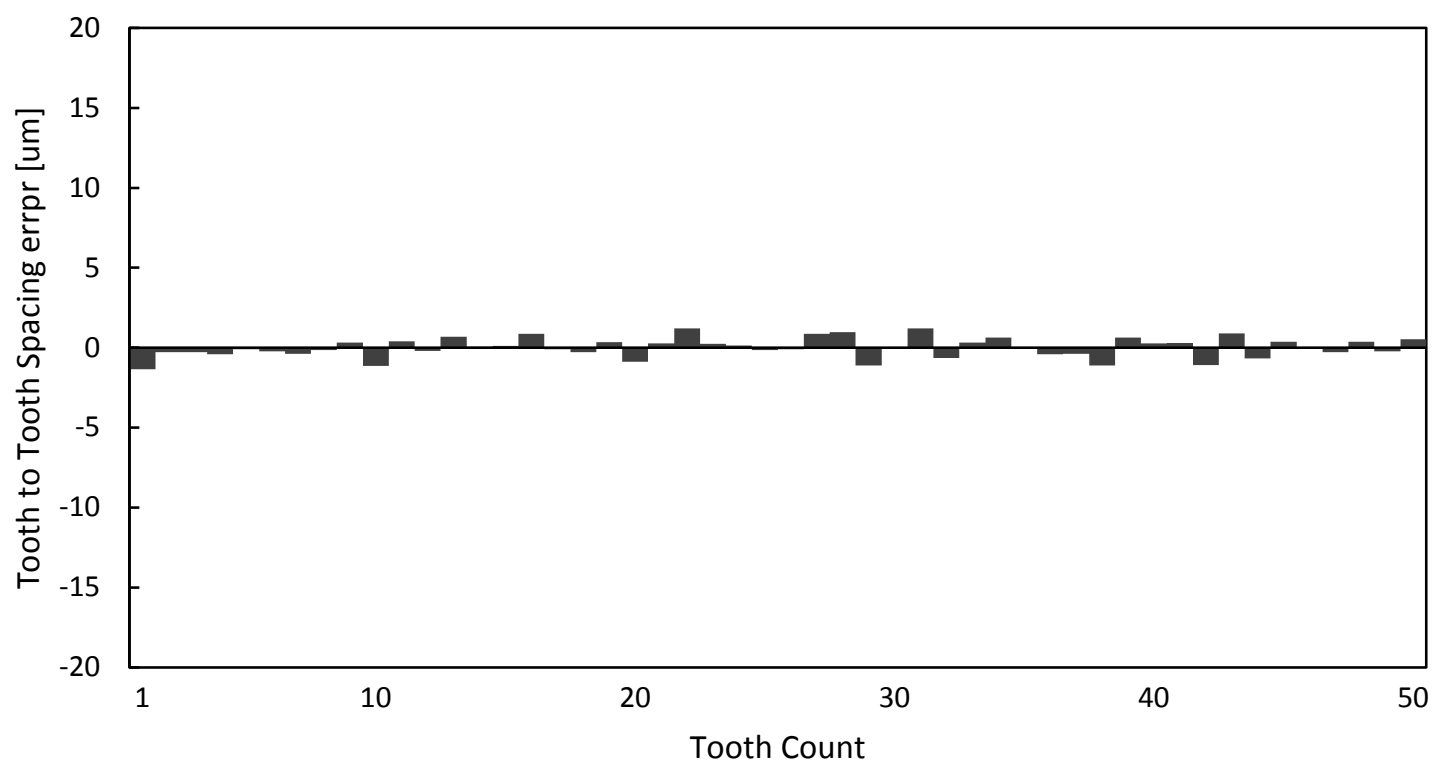

Figure 2.6: Measured tooth-to-tooth spacing errors of test gears (a)\#1, (b) \#2 and (c) \#3. 
(c)

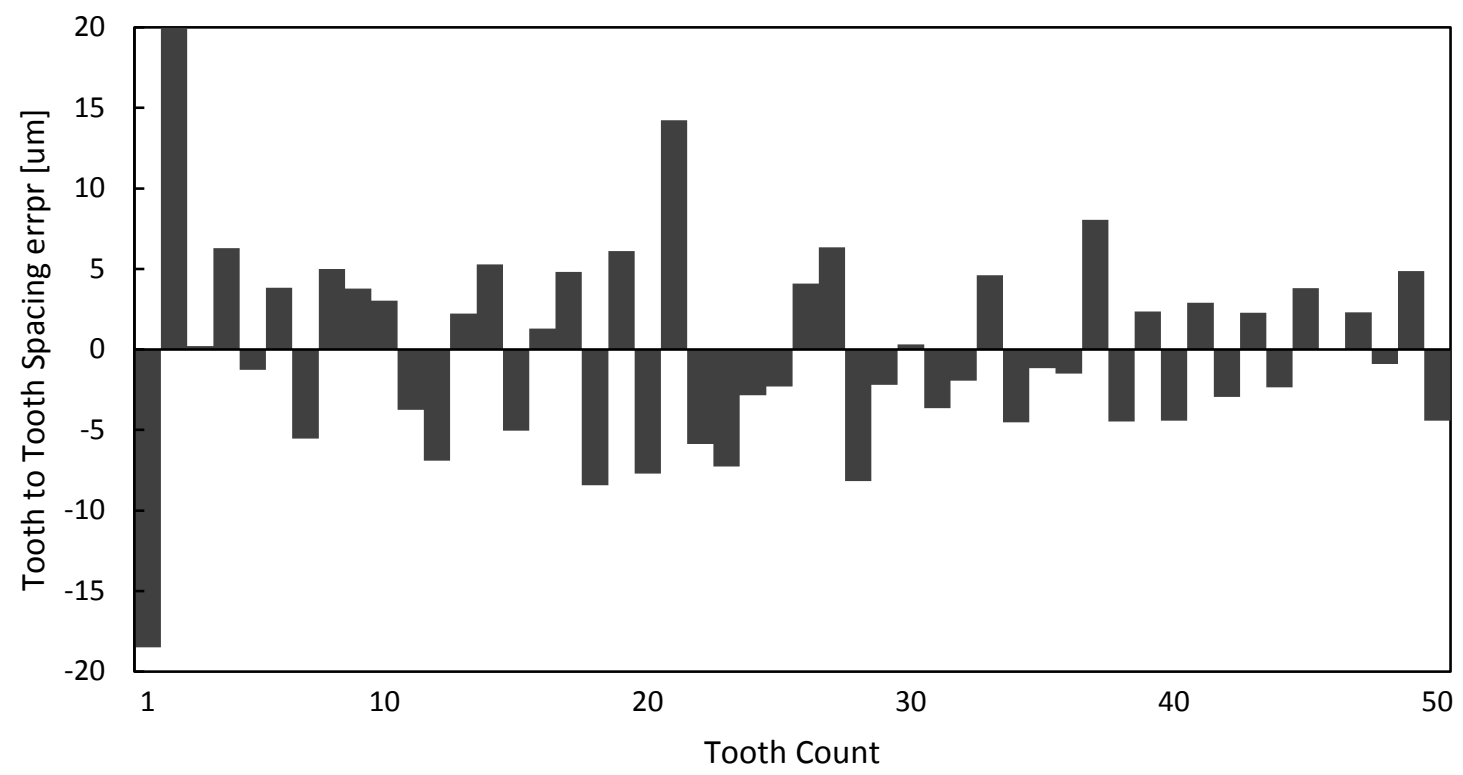

Figure 2.6 (cont.) 
Table 2.3: Test matrix utilized in this study.

\begin{tabular}{cccc}
\hline Test No. & Gear Pair & Torque $[\mathrm{Nm}]$ & Description \\
\hline 1 & $\# 1-\# 2$ & 100 & No error baseline \\
2 & & 200 & \\
3 & & 300 & Randomly sequenced indexing \\
4 & & 100 & errors \\
5 & & 200 & \\
6 & 300 & & \\
\hline
\end{tabular}


Figure 2.7. A recent study looking into the effects of isolated indexing errors on the dynamic transmission error of a spur gear pair et al [26] utilized three mounted tri-axial accelerometers on the driven gear. It was concluded that negligible vibrations existed in the axes outside of the tangential acceleration direction, showing that the employment of uni-axial accelerometers are sufficient for the purposes of this study. With the four uniaxial accelerometers mounted, the two accelerometers on the pinion gear measure tangential accelerations $a_{1}$ and $a_{2}$. These acceleration signals have the following content $[15,25]$

$$
\begin{aligned}
& a_{1}(t)=\rho \ddot{\theta}_{p}(t)+g \sin \left(\omega_{p} t\right), \\
& a_{2}(t)=\rho \ddot{\theta}_{p}(t)-g \sin \left(\omega_{p} t\right) .
\end{aligned}
$$

The two accelerometers on the driven gear measure tangential accelerations $a_{3}$ and $a_{4}$, which are given by the equations

$$
\begin{aligned}
& a_{3}(t)=\rho \ddot{\theta}_{g}(t)+g \sin \left(\omega_{g} t\right), \\
& a_{4}(t)=\rho \ddot{\theta}_{g}(t)-g \sin \left(\omega_{g} t\right) .
\end{aligned}
$$

Here $\ddot{\theta}_{p}(t)$ and $\ddot{\theta}_{g}(t)$ are the measured tangential accelerations for the pinion gear and the driven gear, respectively, $\omega_{p}$ and $\omega_{g}$ are the angular velocities of the pinion and gear, respectively, and $g$ is the gravitational acceleration. These signals are combined to eliminate gravity terms such that the angular accelerations for the pinion and the gear, respectively, can be obtained as 
(a)
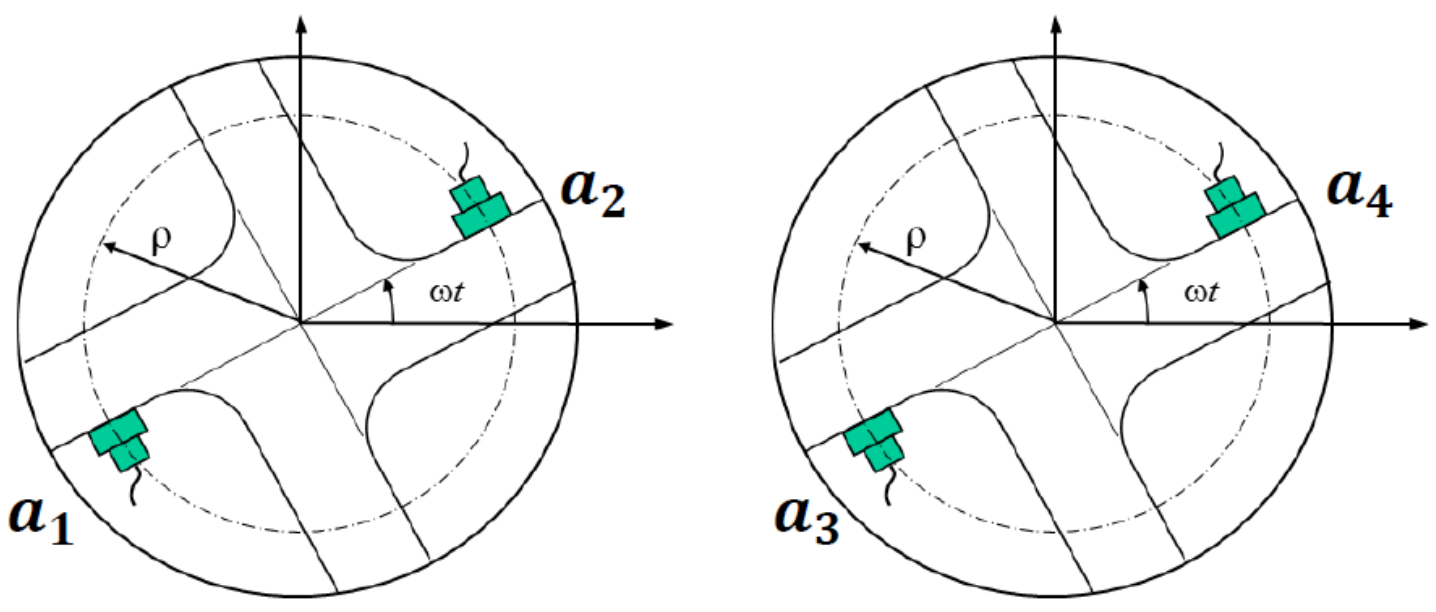

(b)

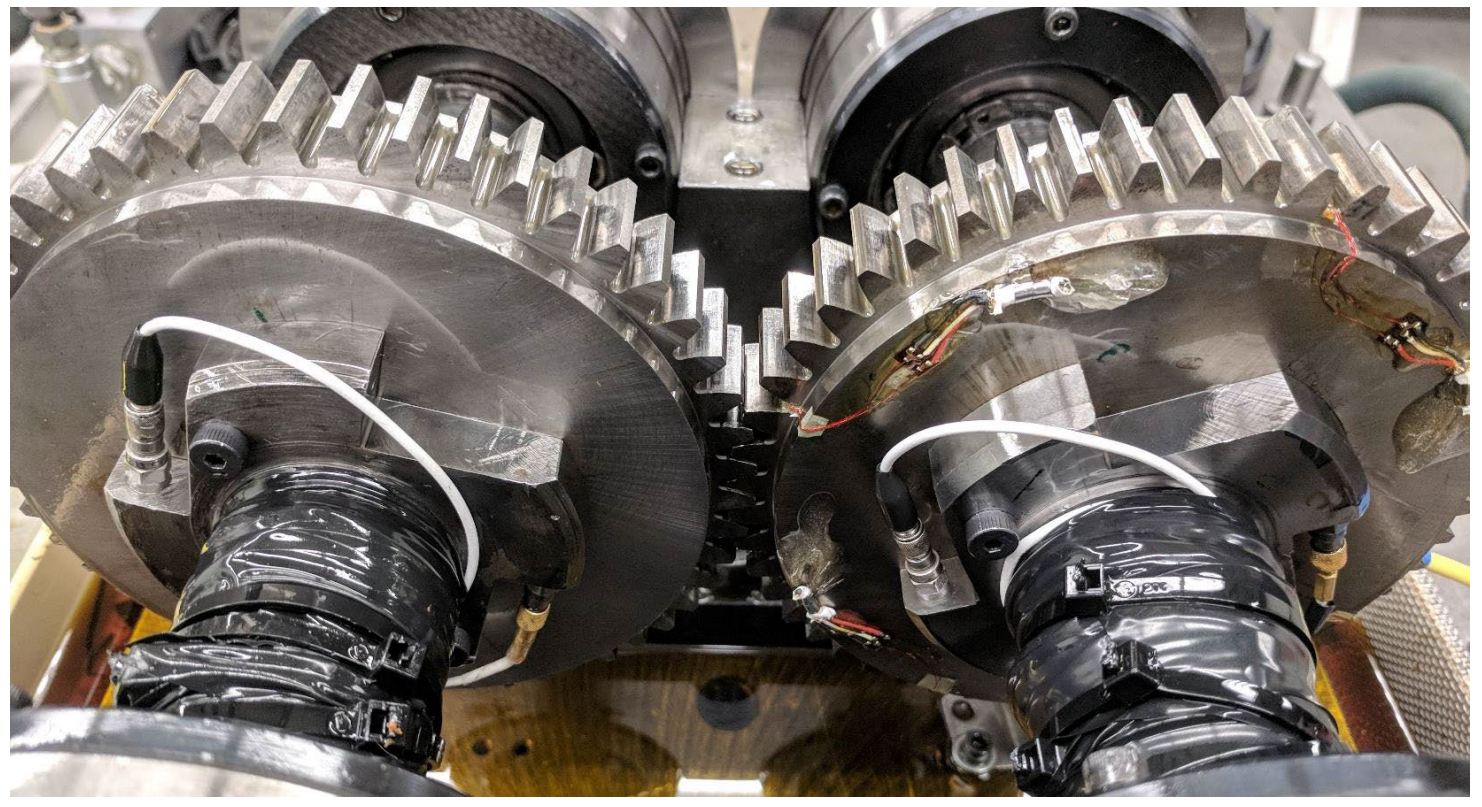

Figure 2.7: (a) Schematic of uniaxial accelerometers mounted on the hubs of each gear, and (b) their implementation a test gear pair (adapted from Ref. [25]). 


$$
\begin{aligned}
& \ddot{\theta}_{p}(t)=\frac{1}{2 \rho}\left[a_{1}(t)+a_{2}(t)\right], \\
& \ddot{\theta}_{g}(t)=\frac{1}{2 \rho}\left[a_{3}(t)+a_{4}(t)\right] .
\end{aligned}
$$

Summing the angular accelerations shown in Eq. (2.2) and multiplying each acceleration by their respected base circle radii, $r_{p}$ and $r_{g}$, results in the second time derivative of the dynamic transmission error (DTE),

$$
\ddot{\delta}(t)=r_{p} \ddot{\theta}_{p}(t)+r_{g} \ddot{\theta}_{g}(t)
$$

Eq. (2.3) is integrated to solve for the first derivative $\dot{\delta}(t)$, and then integrated a second time to obtain the DTE as

$$
\delta(t)=\iint\left[r_{p} \ddot{\theta}_{p}(t)+r_{g} \ddot{\theta}_{g}(t)\right] d t d t
$$

DTE has long been considered as a metric for vibration behavior of a gear pair. This DTE time history is examined in frequency domain to obtain the FFT spectrum of DTE, denoted by $\delta(\omega)$. Measurement and processing of DTE is shown in the block diagram in Figure 2.8 .

The uni-axial accelerometers (PCB Piezotronics 353B18) used to capture the acceleration on the gears have frequency ranges up to $10 \mathrm{kHz}$, which allows for data collection beyond the primary mesh frequency of the system where most of the frequency response is relatively linear throughout the whole operating frequency range. The first three harmonic frequencies are captured accurately even at the highest operating speed, while the fourth and fifth harmonic frequencies are captured adequately enough for 


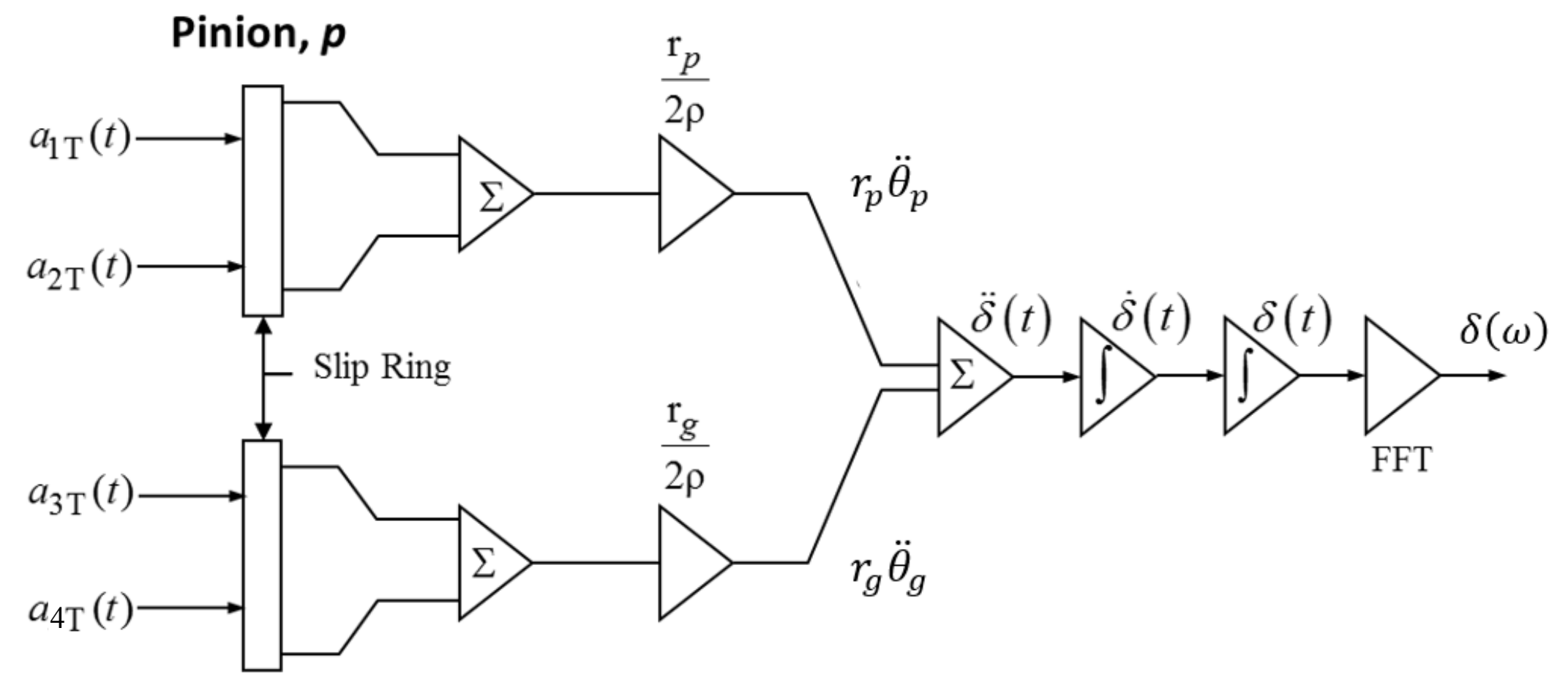

\section{Gear, $g$}

Figure 2.8: Block diagram outlining the calculation of dynamic transmission error (adapted from reference [25]). 
qualitative analysis. A block diagram of the whole data acquisition system is shown in Figure 2.9. The signals from the two accelerometers are fed through hollow shafts where the gears are mounted and connected to a 10-pin channel slip ring (Michigan Scientific SR10M) located at the end of each shaft. Each accelerometer includes a signal wire and a ground wire, such that the two uni-axial accelerometers mounted on each gear use up only four of the ten available pin connections on the slip ring attached on a given shaft. The wiring for the slip ring and accelerometer connections are shown in Figure 2.10 and 2.11. The signals passing through the slip rings are then wired into co-axial connections (where one accelerometer is fed into one connection) and then fed into multichannel signal conditioner (PCB Piezotronics ICP 483MP2) for ICP based sensor excitation and basic signal amplification. The signal then follows through to an analog-to-digital converter (National Instruments PXI-4472) which feeds into a data acquisition chassis (National Instruments PXI-1042), and finally goes into a PC computer through a remote control module (National Instruments PXI-8360). Separate LabVIEW programs control the data acquisition processes depending on either steady-state or transient data collection tests.

\subsection{Data Processing}

The two separate LabVIEW programs used to process the data in this study were first developed and utilized by Anichowski et al [26]. One LabVIEW program is designed to process the steady-state data test, which consists of increments of $25 \mathrm{rpm}$ between a range of operating speeds of 500 to $4200 \mathrm{rpm}$, with a $13 \mathrm{rpm}$ offset for down-sweep compared to upsweep. The program verifies that the machine is in a steady-state speed condition prior to data collection for each speed by monitoring the once-per-revolution 


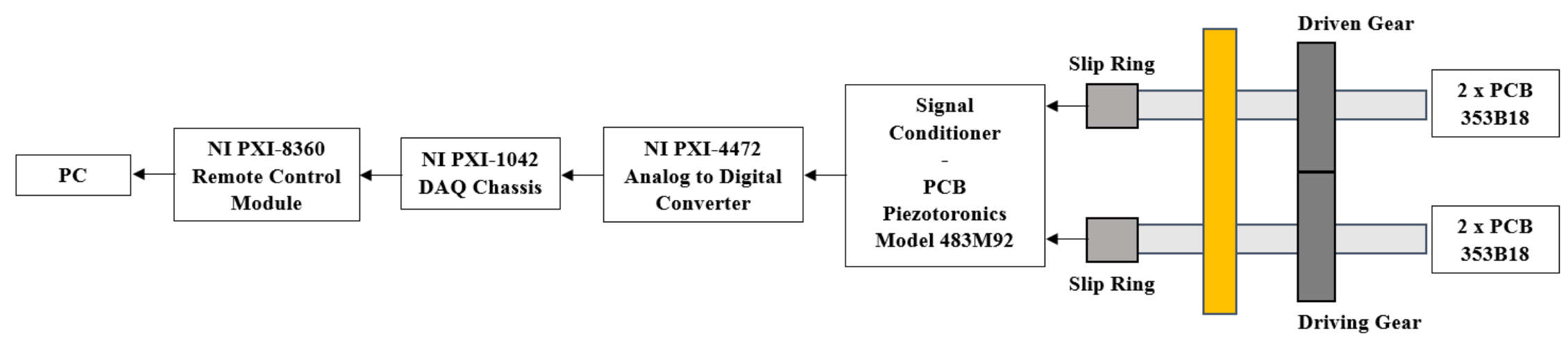

Figure 2.9: Block diagram and schematic of the data acquisition system. 


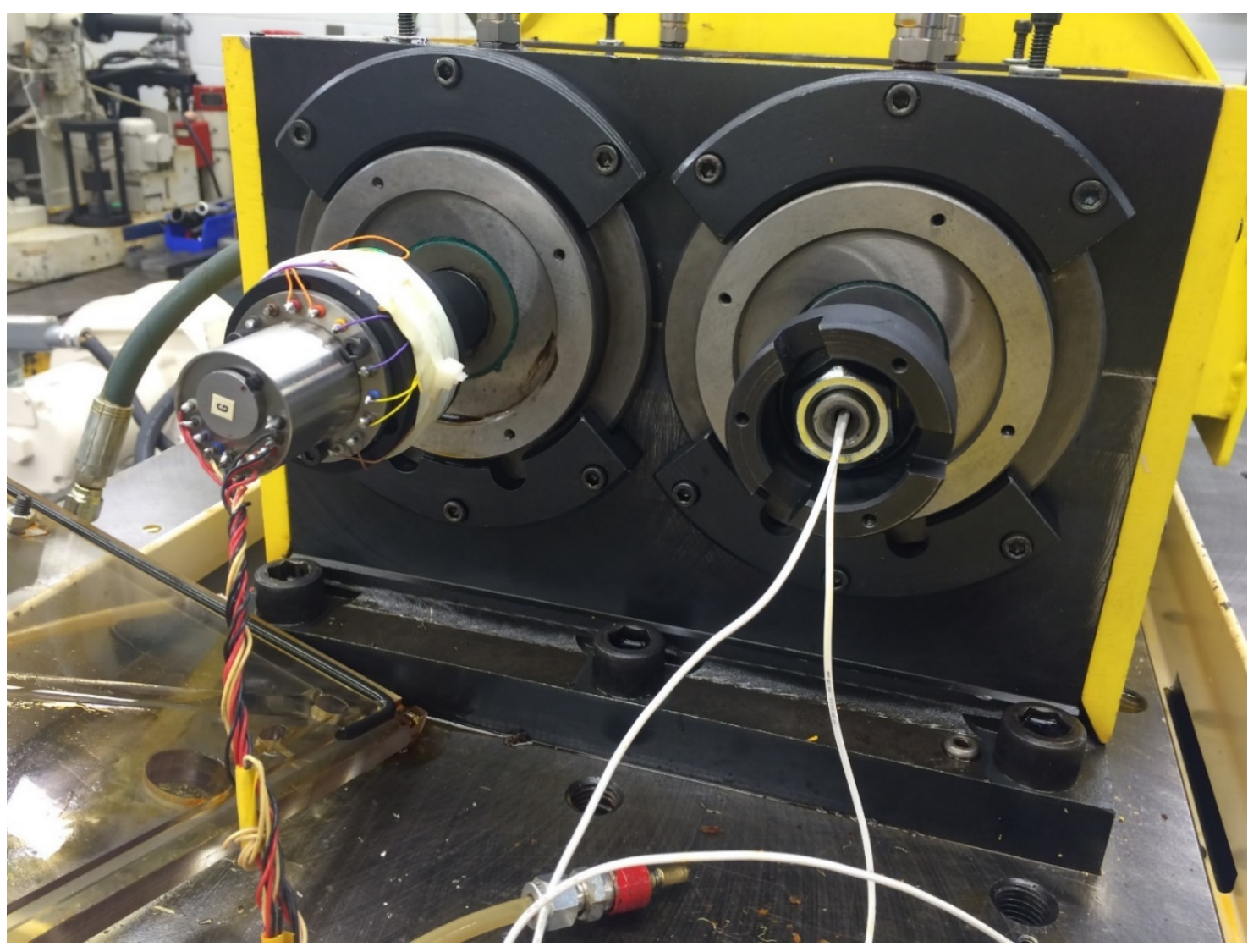

Figure 2.10: Slip ring orientations at the end of test gear shafts. The right shaft shows the hollow configuration through which the wires from the accelerometer(s) were passed, while the left shaft shows an example of the 10-channel slip ring utilized in this study (adapted from reference [25]). 


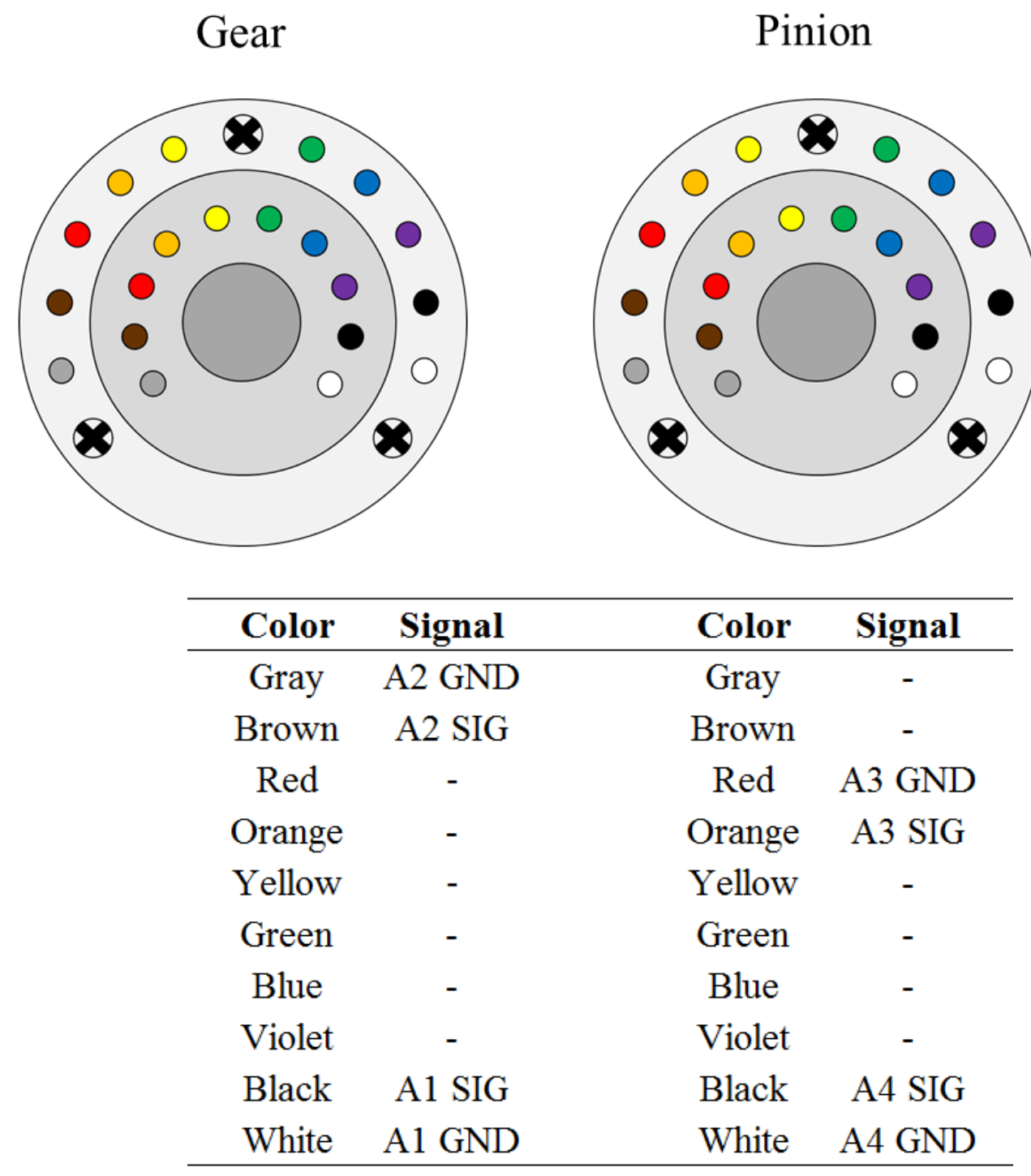

Figure 2.11: Schematic of slip ring wiring for both gear and pinion shafts, utilizing four uniaxial accelerometers (adapted from reference [25]). 
tachometer signal and comparing it to the previous second of data. Once the program determines the machine is in steady state speed condition for an adequate time, one second of data is captured at a sampling frequency of $100 \mathrm{kHz}$. Considering the frequency range up to $10 \mathrm{kHz}$ for each accelerometer, this sampling frequency is well above the Nyquist frequency of $20 \mathrm{kHz}$ for each accelerometer. The program designed to process the transient test is much simpler as compared to the steady state test program. Data collection occurs at a sampling frequency of $40 \mathrm{kHz}$, still two times more than the accelerometer Nyquist frequency, throughout the 6.5 -minute long test consisting of a 3 minute long up-sweep from $500 \mathrm{rpm}$, a 30 second dwell at the upper speed limit of $4200 \mathrm{rpm}$, and a 3 minute long down-sweep back down to $500 \mathrm{rpm}$.

MATLAB codes further process the signal from both steady state and transient data sets captured through the aforementioned LabVIEW programs. The signals captured and given as $\ddot{\delta}(t)$ are put through the MATLAB codes to obtain $\dot{\delta}(t)$ and eventually $\delta(t)$. The MATLAB process, which utilizes a numerical integration, adapted from a code developed and first implemented by Anichowski et al [26], is different from the pseudo-integration method used in other previous studies $[15,31]$.

With the resultant frequency spectra, each mesh harmonic amplitude $A_{n}$ of the $n^{\text {th }}$ mesh harmonic order represents a root mean squared (RMS) of all orders within a frequency band of $\pm 100 \mathrm{~Hz}$ surrounding the harmonic peak $n f_{\text {mesh }}$ given by $f_{\text {mesh }}=\frac{N \cdot \Omega}{60}$. These resultant amplitudes of the first five mesh harmonics define the RMS amplitude of dynamic transmission error, 


$$
A_{r m s}=\sqrt{\sum_{n=1}^{5}\left(A_{n}^{2}\right)} .
$$

This process was repeated at each discrete speed value captured throughout the steady-state test for all torque levels and both sweep directions (up-sweep and down-sweep).

Regarding the MATLAB code for the transient test, the 6.5-minute long transient data set was broken into 500 discrete segments of roughly 0.75 seconds to create quasisteady state data sets. The aforementioned process for steady state data sets applies to these discrete quasi-steady state data sets to process the data accurately. The processed data was presented in the form of waterfall plots from up-sweep and down-sweep sections of the transient data. The data collected from the 30-second dwell state of the transient test was discarded. 


\section{CHAPTER 3}

\section{EXPERIMENTAL RESULTS \& DISCUSSION}

\subsection{Introduction}

This chapter presents the results obtained through execution of the proposed experimental test matrix given in Chapter 2. Section 3.2 presents the dynamic response of the no-error gear pair (gear pair \#1-\#2) to serve as the baseline dynamic behavior, while Section 3.3 presents the measured dynamic behavior of a gear pair with random indexing errors (gear \#1-\#3). Experimental results are presented in both sections in the following formats:

(i) Forced response curves generated by plotting the root-mean-square (RMS) DTE amplitude, $A_{r m s}$, calculated according to Eq. (2.6) against the mesh frequency

$f_{\text {mesh }}=\frac{N \cdot \Omega}{60}$ (in Hz) from the steady-state tests. These plots overlay the data point collected during the up and down sweeps for each torque increment considered (100, 200 and $300 \mathrm{Nm})$. 
(ii) Plots depicting the time variation of the steady-state vibration signals at given speeds (or $f_{\text {mesh }}$ ) including $\ddot{\delta}(t)$ over 70 gear mesh cycles to show its repeatability over gear revolution period, a phase-plane plot of $\ddot{\delta}(t)$ versus $\dot{\delta}(t)$, and the frequency spectrum of $\delta(t)$ highlighting the gear mesh order frequencies.

(iii) Waterfall plots of $\delta(t)$ with mesh frequency $f_{m e s h}$ in $\mathrm{Hz}$ and rotational speed $\Omega$ in rpm as the controlled parameters. These are calculated from quasi-steady state subsets of data from the down-sweep condition transient experimental results.

\subsection{Baseline Results}

The baseline test consists of a set of steady-state and transient tests performed using the gear pair of negligible spacing errors (gears \#1-\#2). Figure 2.6(a-b) show the measurements of these gears, with the basic gear design parameters displayed in Table 2.1. The steady-state tests were performed within the speed range of 500 to $4200 \mathrm{rpm}$ for both up-sweep and down-sweep conditions, corresponding to a $f_{m e s h}$ range of 416 to $3500 \mathrm{~Hz}$. These tests performed at loaded torques of 100, 200, and $300 \mathrm{Nm}$ are as shown in tests \#1, $\# 2$ and \#3 in Table 2.3 .

Figure 3.1 shows this $A_{r m s}$ against $f_{m e s h}$ overlaying all torques tested given the sweep direction. Figure 3.2 presents the same data by overlaying the data points for up and down sweep conditions at a given torque value. Some observations from these plots are listed below: 

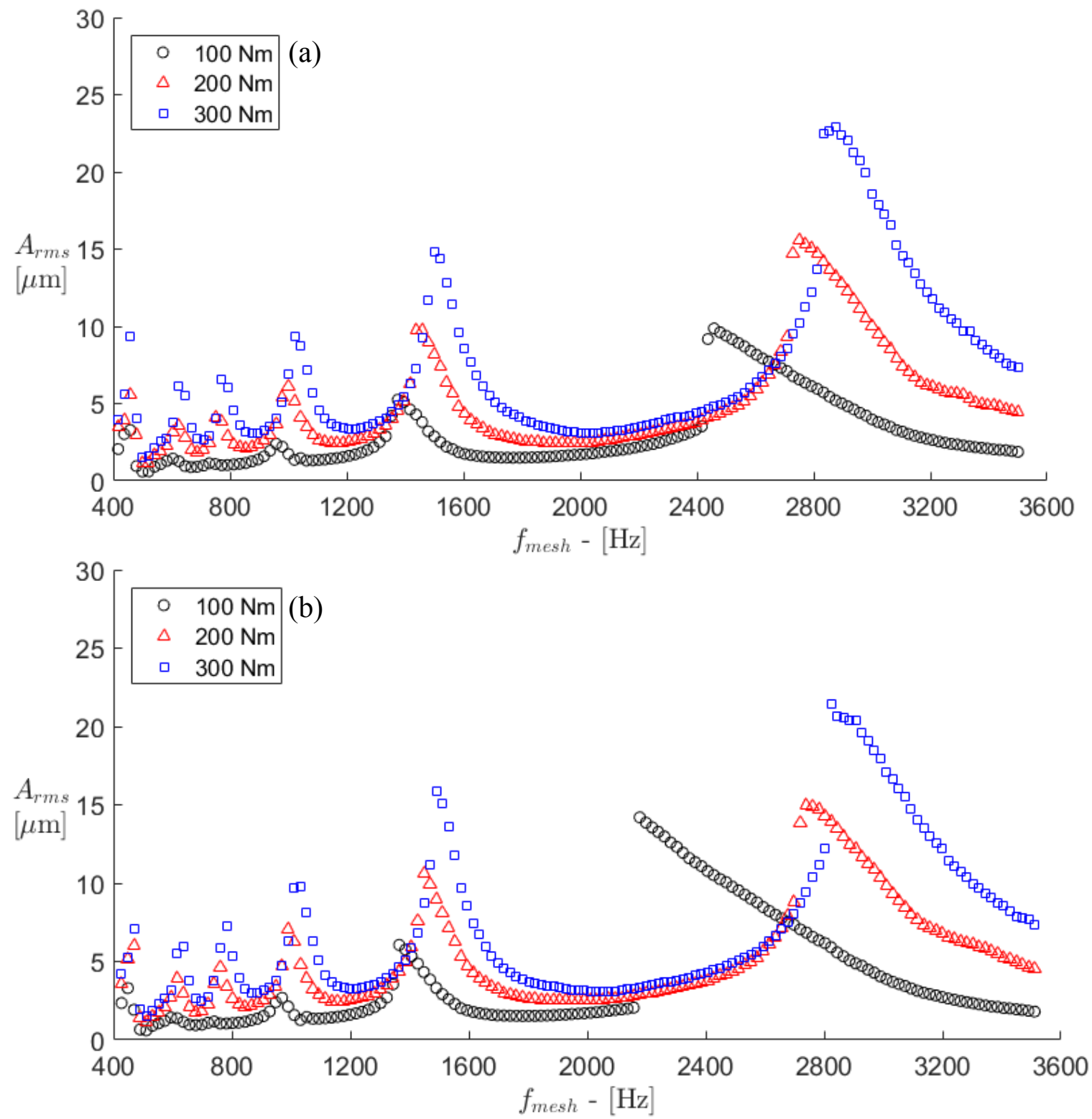

Figure 3.1: RMS DTE amplitudes, $A_{r m s}$, of the no-error gear pair at 100, 200, and 300 $\mathrm{Nm}$ in (a) up-sweep and (b) down-sweep conditions. 

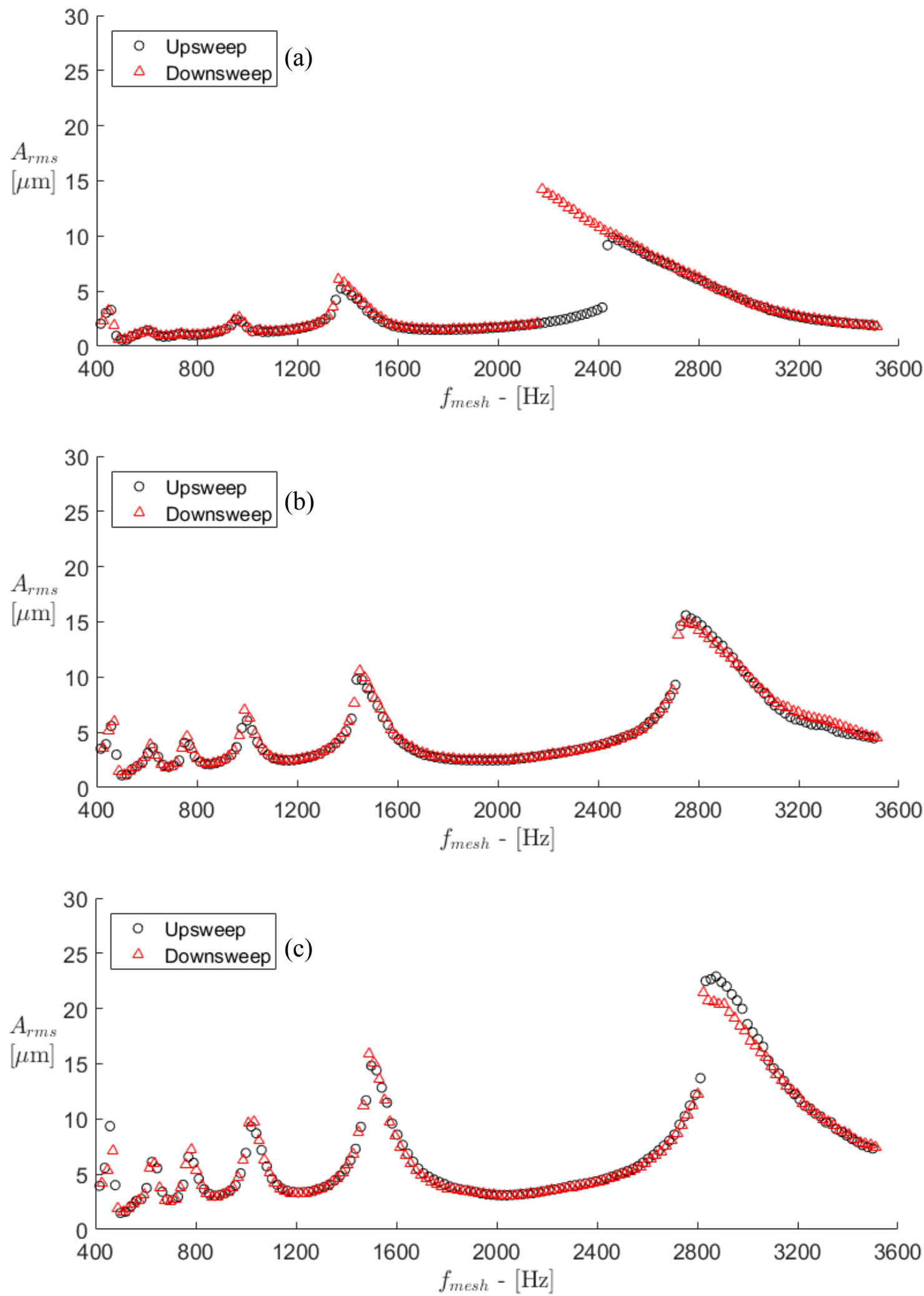

Figure 3.2: RMS DTE amplitudes, $A_{r m s}$, of the no error gear pair under up and downsweep conditions at (a) $100 \mathrm{Nm}$, (b) $200 \mathrm{Nm}$, and (c) $300 \mathrm{Nm}$. 
- DTE RMS amplitude $A_{r m s}$ increases at both the gear mesh harmonic frequencies and off-resonant shaft harmonic frequencies as torque increases.

- A purely torsional response exists as only a single natural frequency is excited within the operating range of the gear pair. This gear pair natural frequency is observed to increase with torque. This is due to an increase in gear mesh stiffness that comes with an increase in tooth contact along the face of the tooth in mesh as the loaded torque increases. The natural frequencies occur at $f_{\text {nat }} \approx 2750,3050$, and $3150 \mathrm{~Hz}$ for torques 100,200 , and $300 \mathrm{Nm}$, respectively.

- Behavior in both up-sweep and down-sweep conditions are identical or repeatable for most frequencies tested. An exception occurs at the primary resonance peak near the natural frequency for $100 \mathrm{Nm}$, where there exists a jump-discontinuity between both sweep conditions. The up-sweep condition exhibits a lower branch of $A_{r m s}$ and the down-sweep condition exhibits an upper branch of $A_{r m s}$. This behavior suggests a softening type nonlinear behavior due to tooth contact loss when the gear pair reaches speeds at resonance near natural frequency.

- Nonlinear behavior diminishes with increases in torque, shown by the jumpdiscontinuity present in the $100 \mathrm{Nm}$ condition, but not for the 200 and $300 \mathrm{Nm}$ torque condition. In addition, asymmetry of peaks at natural frequencies, which correlate to non-linear behavior, reduces as torque increases.

- Super-harmonic resonance peaks occur at $n f_{\text {mesh }} \approx f_{\text {nat }}$ (where $n=2,3$, and 4) caused by the second through fourth harmonics of the gear mesh excitation. None 
of these super-harmonic resonance peaks exhibit significant non-linear behavior, suggesting that tooth separations do not take place at these frequencies.

In addition to forced response curves of the baseline no-error gear pair, timedomain behavior and the corresponding frequency content were also examined. Figures 3.3 to 3.8 provide these at selected mesh frequency values using (a) the raw acceleration signals $\ddot{\delta}(t)$ analyzed over 70 gear mesh cycles, which is 1.4 times a full rotation period of a 50 tooth unity-ratio gear pair, (b) phase-plane plots of $\ddot{\delta}(t)$ against $\dot{\delta}(t)$ to highlight repeatability of each gear mesh period and (c) Fast Fourier Transforms (FFT spectrum) of $\delta(t)$ showing the frequency content and the amplitudes associated with each frequency. Gear mesh harmonic frequencies are marked by symbols " $\mathrm{x}$ " along the $\mathrm{x}$-axis of each FFT spectrum. Steady-state motions shown in Figures 3.3 to 3.8 are at $f_{\text {mesh }}=1083,1375$, 1792, 2282, 2292, and $2450 \mathrm{~Hz}$, respectively, which correspond to rotational speeds of $\Omega=1300,1650,2150,2738,2750$, and $2950 \mathrm{rpm}$. All time histories shown are for the up-sweep condition with the exception of the $2282 \mathrm{~Hz}$ condition being down-sweep. Some relevant observations from these time history plots of motion are stated below:

- Measured vibrations are periodic at the rotational period of the gears as the segments of $\ddot{\delta}(t)$ within mesh cycles 1-20 and 51-70 appear identical. As such, these segments of data coincide on the phase plane plots. This indicates that the conditions at which the data collected were indeed steady state.

- A periodicity of the time histories at the gear mesh period is also evident.

- A majority of $\delta(t)$ amplitudes in the FFT spectra are seen to be associated with 

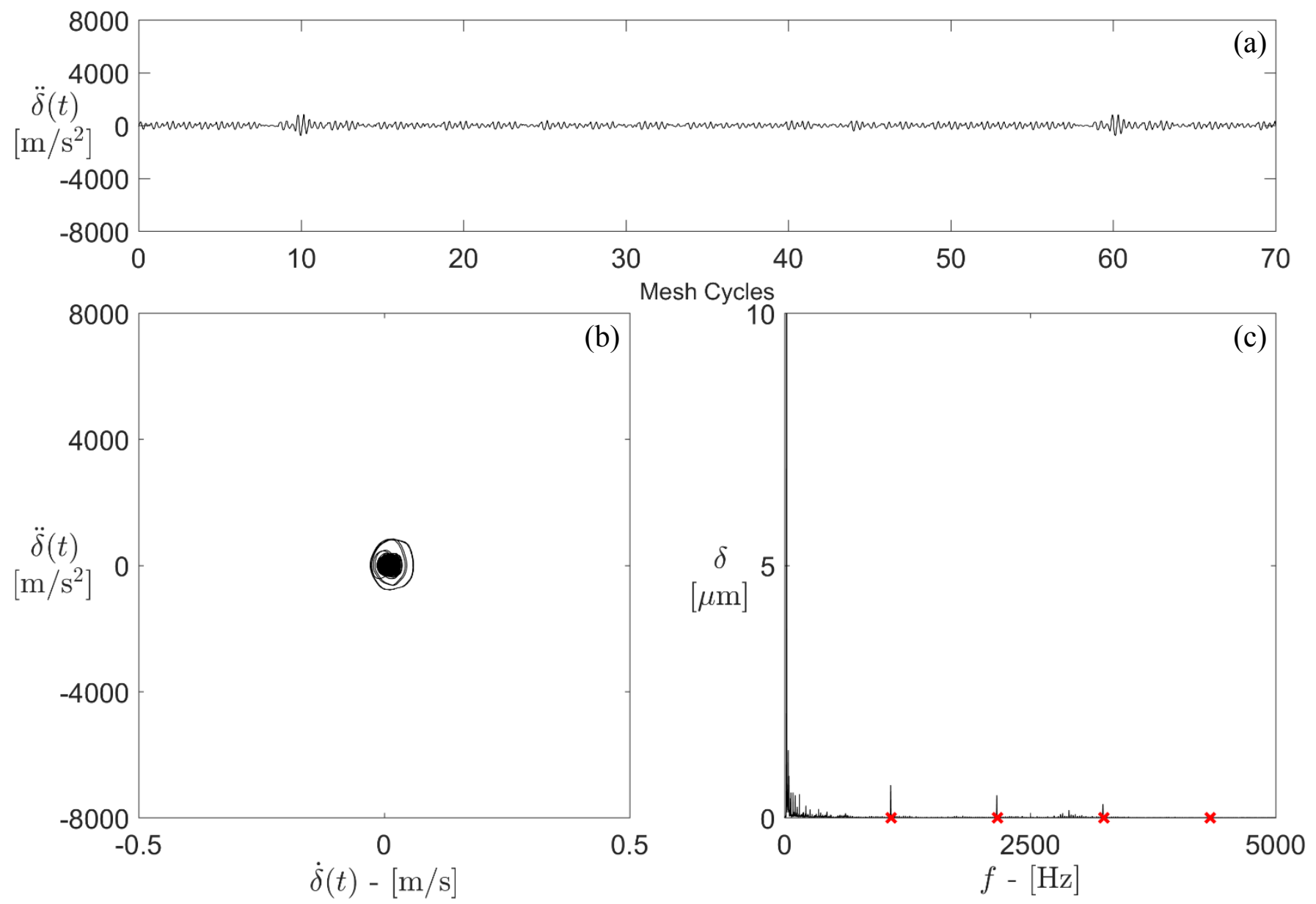

Figure 3.3: (a) $\ddot{\delta}(t)$ versus mesh cycles, (b) $\ddot{\delta}(t)$ versus $\dot{\delta}(t)$, and (c) FFT spectrum of the no-error spur gear pair at $100 \mathrm{Nm}, f_{m e s h}=$ $1083 \mathrm{~Hz}$ (up-sweep) in between the first and second super-harmonic peak. 

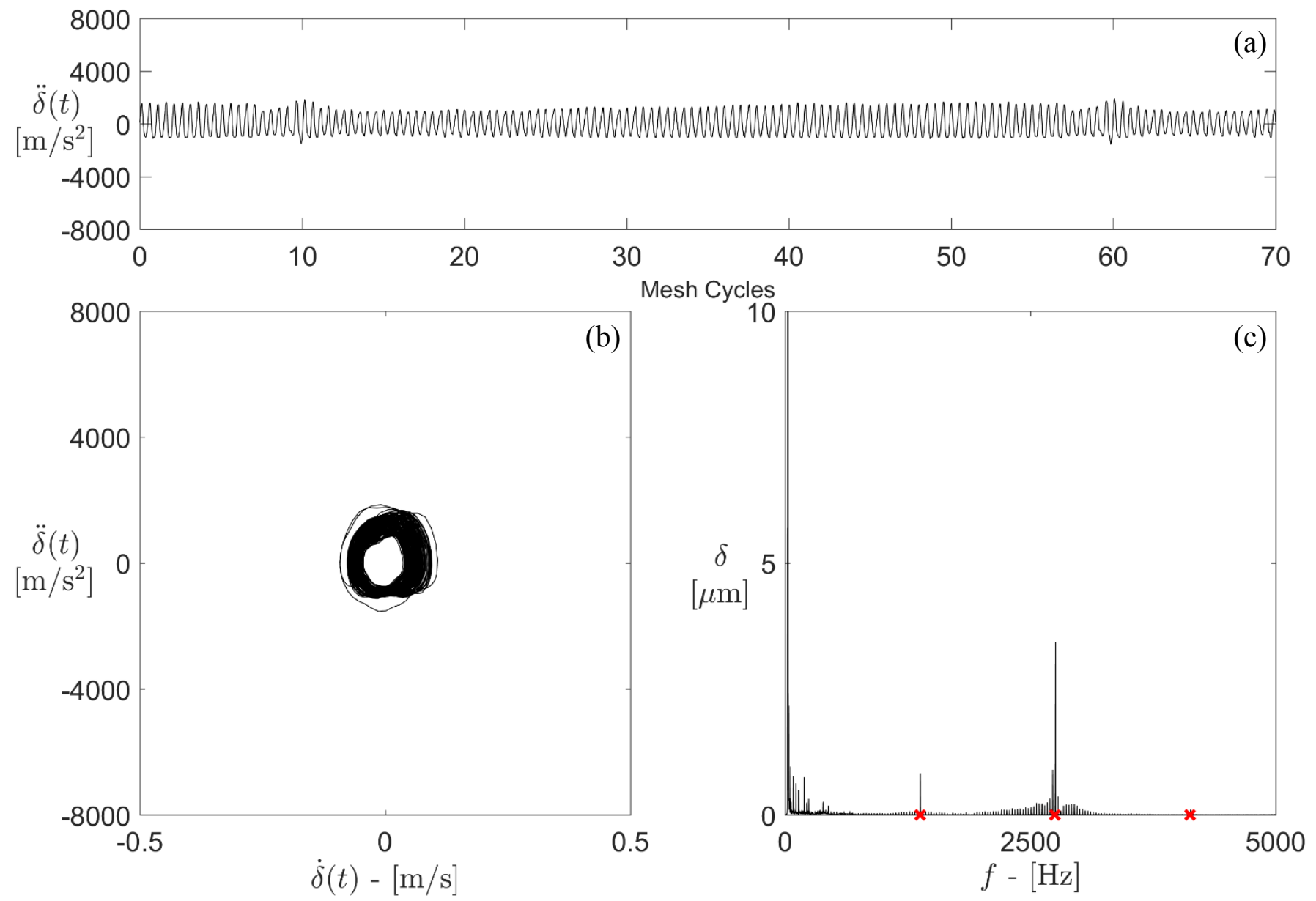

Figure 3.4: (a) $\ddot{\delta}(t)$ versus mesh cycles, (b) $\ddot{\delta}(t)$ versus $\dot{\delta}(t)$, and (c) FFT spectrum of the no-error spur gear pair at $100 \mathrm{Nm}, f_{\text {mesh }}=$ $1375 \mathrm{~Hz}$ (up-sweep) at the first super-harmonic peak. 

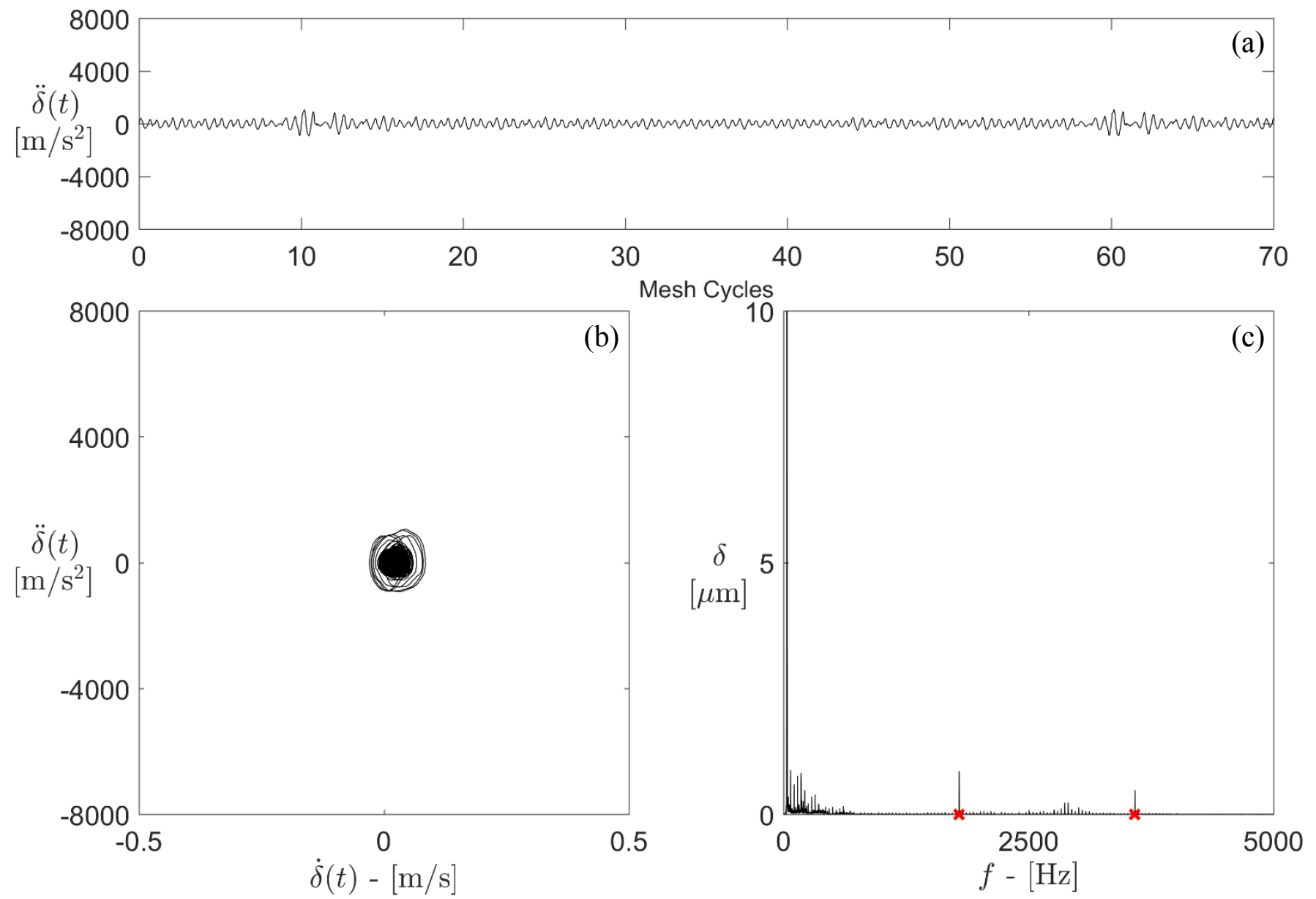

Figure 3.5: (a) $\ddot{\delta}(t)$ versus mesh cycles, (b) $\ddot{\delta}(t)$ versus $\dot{\delta}(t)$, and (c) FFT spectrum of the no-error spur gear pair at $100 \mathrm{Nm}, f_{m e s h}=$ $1792 \mathrm{~Hz}$ (up-sweep) in between the first super-harmonic and primary resonance peak. 

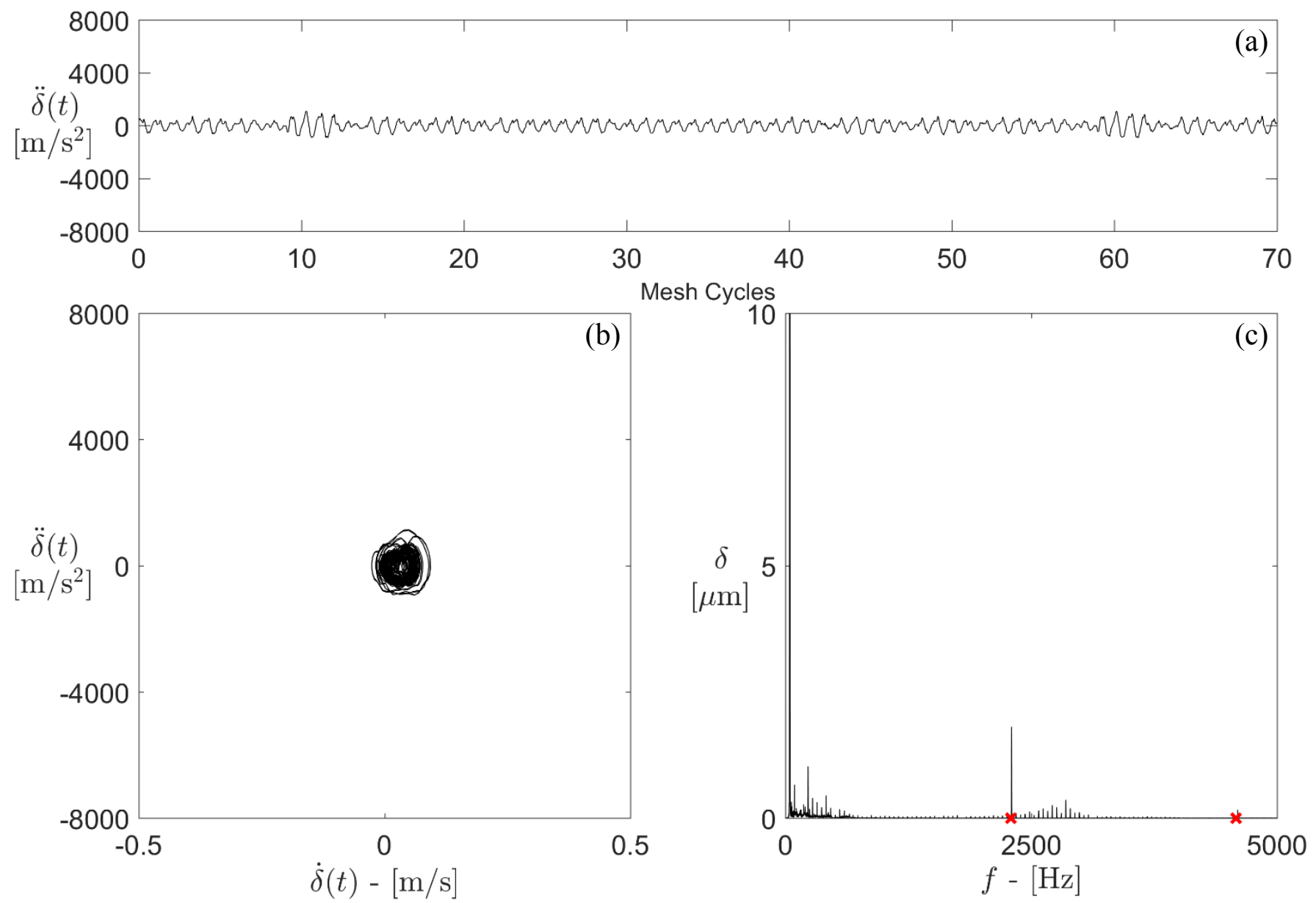

Figure 3.6: (a) $\ddot{\delta}(t)$ versus mesh cycles, (b) $\ddot{\delta}(t)$ versus $\dot{\delta}(t)$, and (c) FFT spectrum of the no-error spur gear pair at $100 \mathrm{Nm}, f_{m e s h}=$ $2292 \mathrm{~Hz}$ (up-sweep) at the lower branch of the jump discontinuity near resonance. 

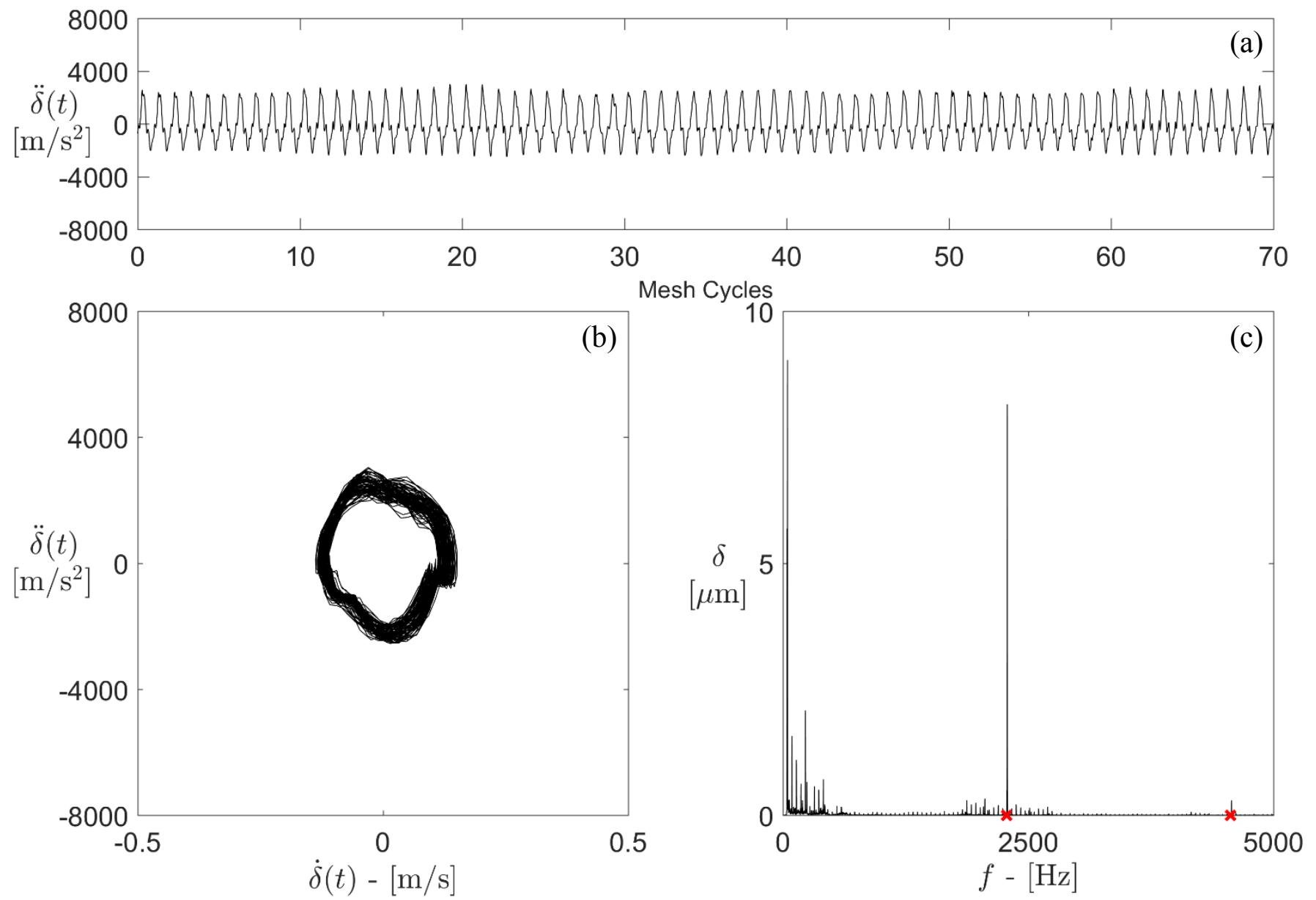

Figure 3.7: (a) $\ddot{\delta}(t)$ versus mesh cycles, (b) $\ddot{\delta}(t)$ versus $\dot{\delta}(t)$, and (c) FFT spectrum of the no-error spur gear pair at $100 \mathrm{Nm}, f_{\text {mesh }}=$ $2282 \mathrm{~Hz}$ (down-sweep) at the upper branch of the jump discontinuity near resonance. 

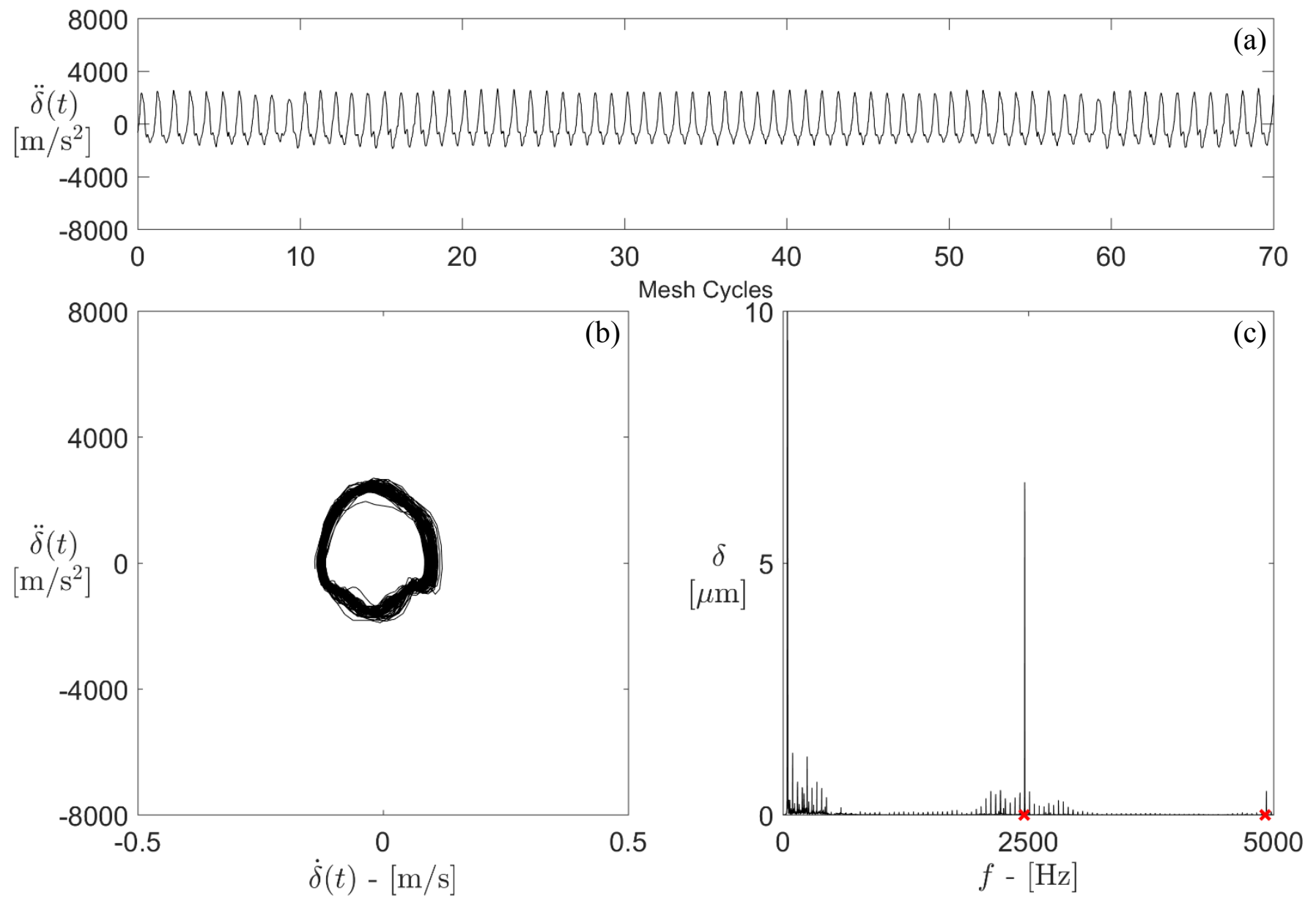

Figure 3.8: (a) $\ddot{\delta}(t)$ versus mesh cycles, (b) $\ddot{\delta}(t)$ versus $\dot{\delta}(t)$, and (c) FFT spectrum of the no-error spur gear pair at $100 \mathrm{Nm}, f_{\text {mesh }}=$ $2450 \mathrm{~Hz}$ (up-sweep) after the jump discontinuity near resonance. 
the gear mesh frequency and its higher harmonics with negligible non-gear mesh frequency content.

- In Figure 3.4 at the first super-harmonic resonance peak, and in Figures 3.7 and 3.8 near primary resonance peak, higher acceleration amplitudes associated with the gear mesh order get larger, showing the periodicity of the signals at the gear mesh period more clearly.

- Small amounts of tooth spacing error that are still present in gears \#1 and \#2, as shown in Figure 2.6(a-b), are seen to cause tooth-to-tooth variations of the measured signals over a complete revolution of the gears. This is particularly evident in the off-resonance frequencies, such as at $f_{\text {nat }}=2750 \mathrm{~Hz}$, where the periodicity over gear mesh is less obvious since the RMS DTE amplitudes are low.

The waterfall plots from the transient tests are presented in Figures 3.9 and 3.10 for the 100 and $300 \mathrm{Nm}$, respectively, all in the down-sweep condition. The up-sweep condition results are near identical to the results shown in the down-sweep condition, with the exception of a jump up at a lower frequency near the primary resonance peak due to the softening type non-linearity. Significant findings from the waterfall plots include the following:

- Distinct diagonals of $\delta(t)$ amplitudes, depicted in yellow peaks, represent the gear mesh orders. Little to no dynamic behavior in the form of $\delta(t)$ amplitude are present outside of the gear mesh orders, which are the shaft harmonic frequencies. 


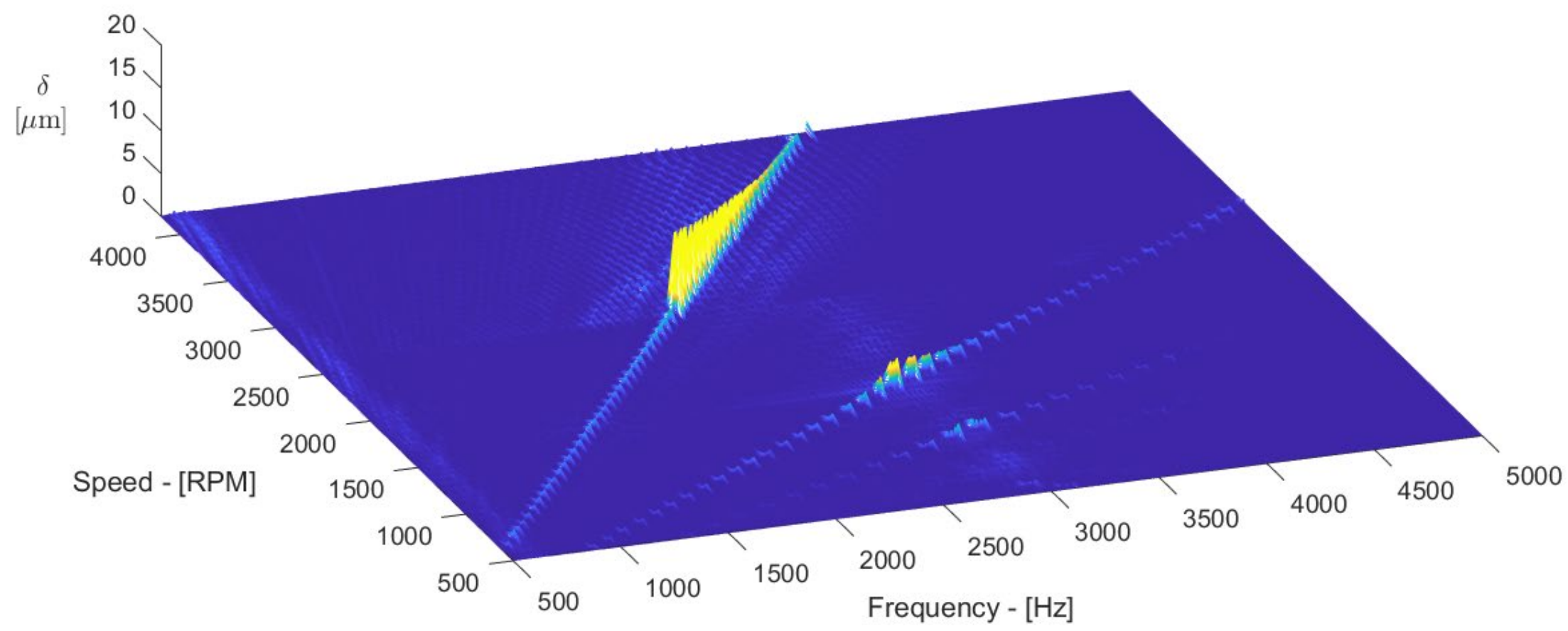

Figure 3.9: Waterfall plot of $\delta(t)$ for the no-error spur gear pair at $100 \mathrm{Nm}$ in the down-sweep condition. 


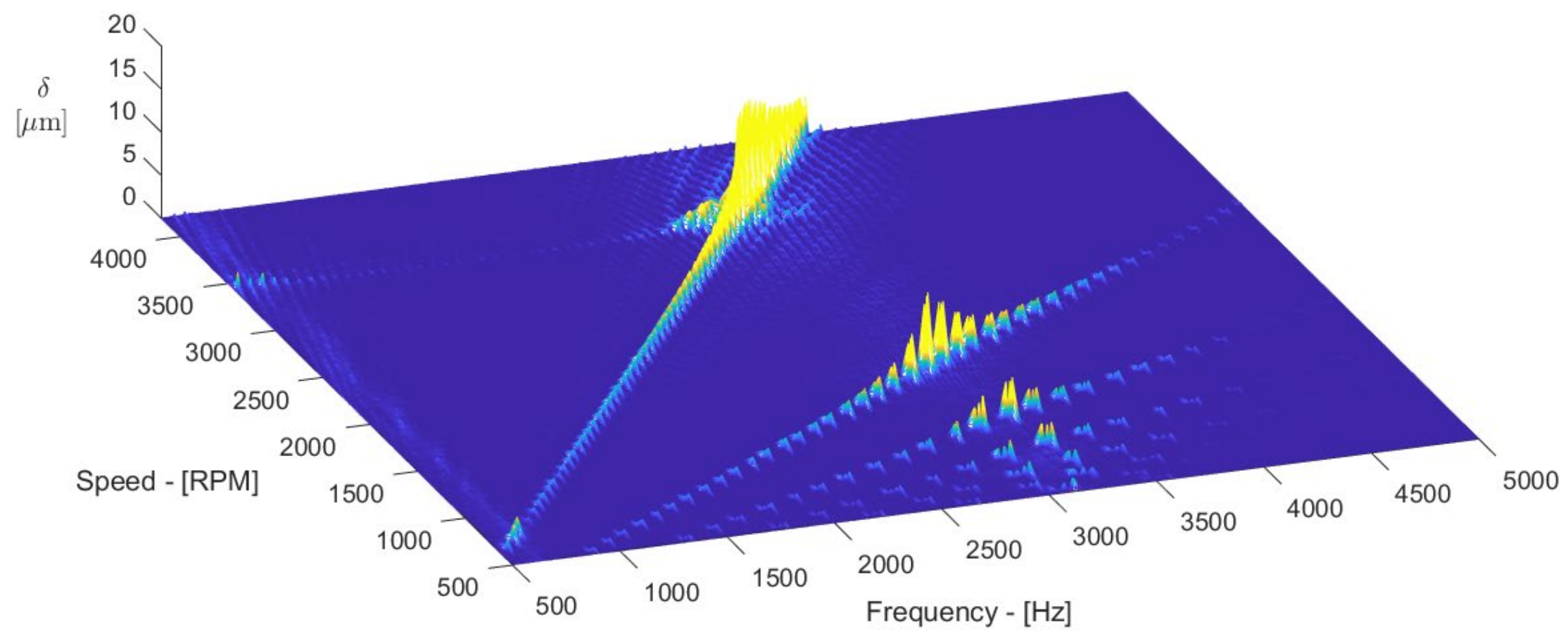

Figure 3.10: Waterfall plot of $\delta(t)$ for the no-error spur gear pair at $300 \mathrm{Nm}$ in the down-sweep condition. 
- The upward shift of natural frequency is further demonstrated in these waterfall plots as the torque increases.

- The presence of dynamic behavior in the form of $\delta(t)$ amplitudes only along the gear mesh orders correlates to a tonal frequency spectrum.

\subsection{Random Error Gear Pair Results}

Results of a gear pair with random spacing errors are extracted from the same type of steady-state and transient tests as the baseline tests. Here, a gear with no spacing error (gear \#1) is paired with a gear having significant magnitudes of randomly sequenced spacing errors (gear \#3). Figure 2.6 (b-c) shows the measurements of the spacing errors on these gears. Given the fact that gear geometry, test set-up, and operating conditions are all the same as the baseline condition, any distinct behavior observed here can be attributable to those random spacing errors. The test matrix of Table 2.3 lists these experiments as tests \#4-\#6.

The forced response curves for gear pair \#1-\#3 are shown in Figures 3.11 and 3.12. In Figures 3.13, forced response curves (both up and down sweep included) for this gear pair at 100, 200 and $300 \mathrm{Nm}$ are compared to those from the baseline, no-error gear pair. From these figures, it is observed that the overall shapes of the forced response curves are not altered by the random spacing errors, where primary and super-harmonic resonance peaks are maintained. Overall amplitudes are slightly lower for the second gear pair, suggesting that vibratory energy was possibly shifted to non-mesh frequency harmonics. as the RMS DTE presented in these figures include only the first five harmonics of the gear 

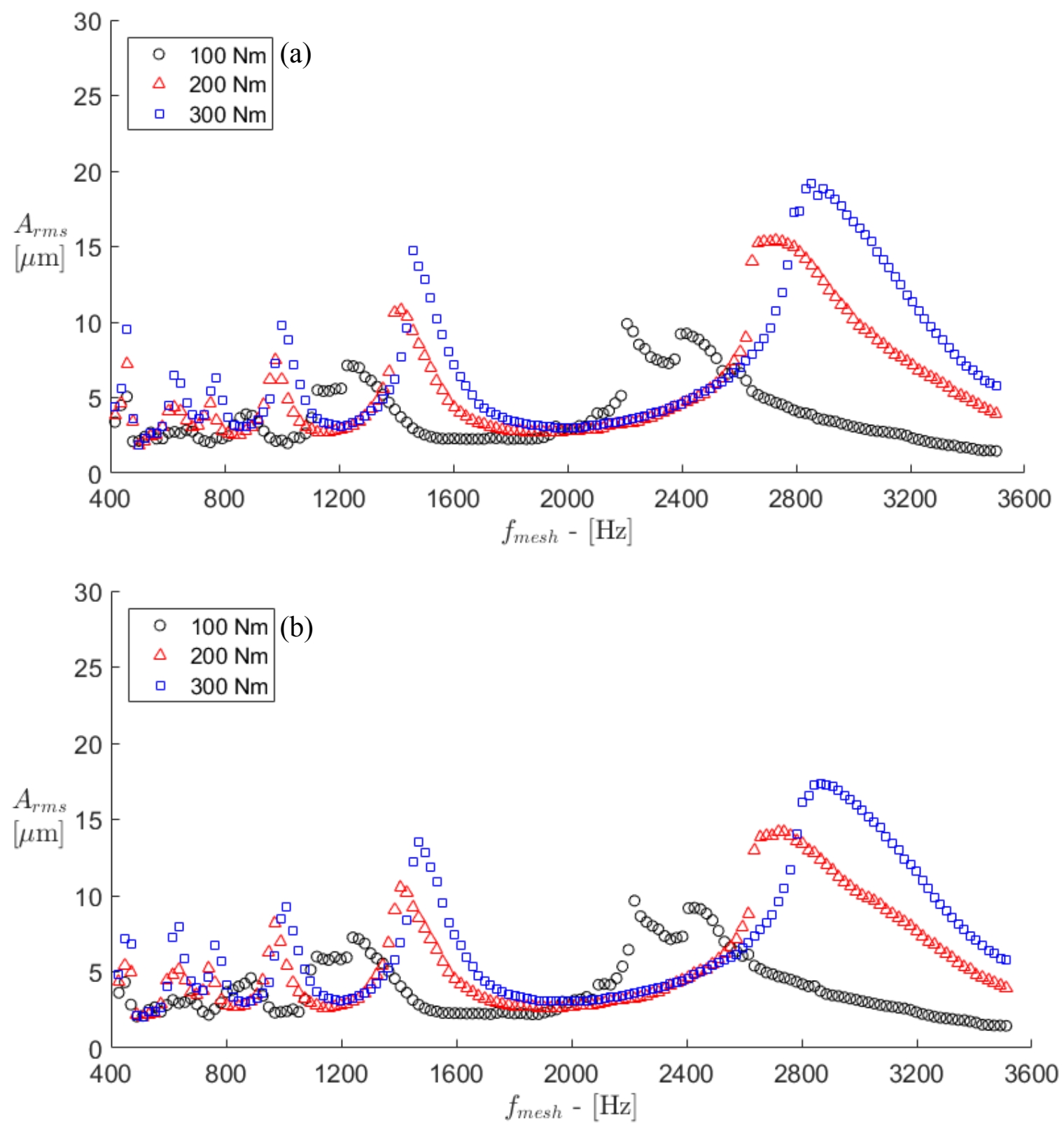

Figure 3.11: RMS DTE amplitudes, $A_{r m s}$, of the random-error gear pair at 100, 200, and $300 \mathrm{Nm}$ in (a) up-sweep and (b) down-sweep conditions. 

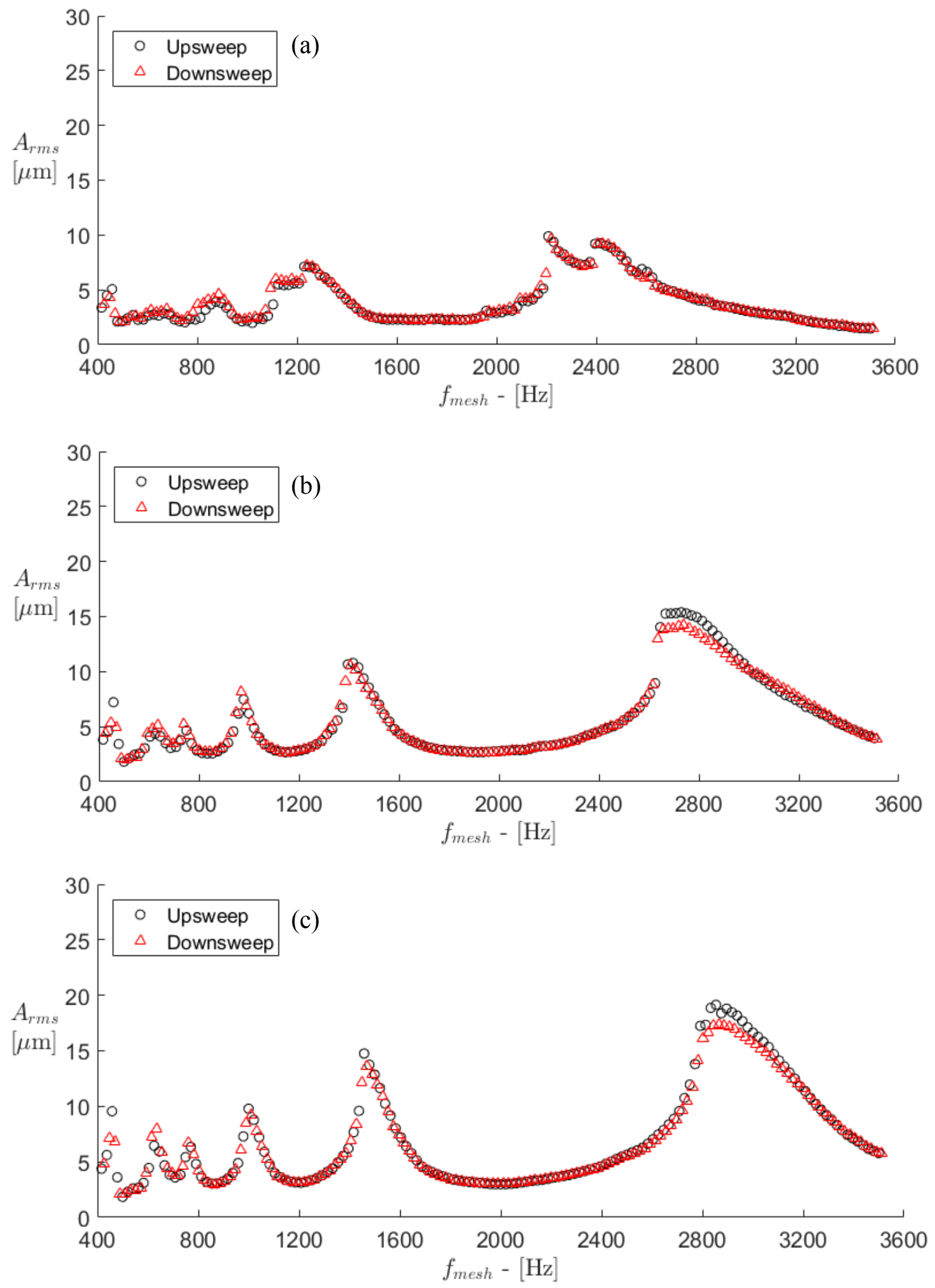

Figure 3.12: RMS DTE amplitudes, $A_{r m s}$, of the random-error gear pair under up and down- sweep conditions at (a) $100 \mathrm{Nm}$, (b) $200 \mathrm{Nm}$, and (c) $300 \mathrm{Nm}$. 

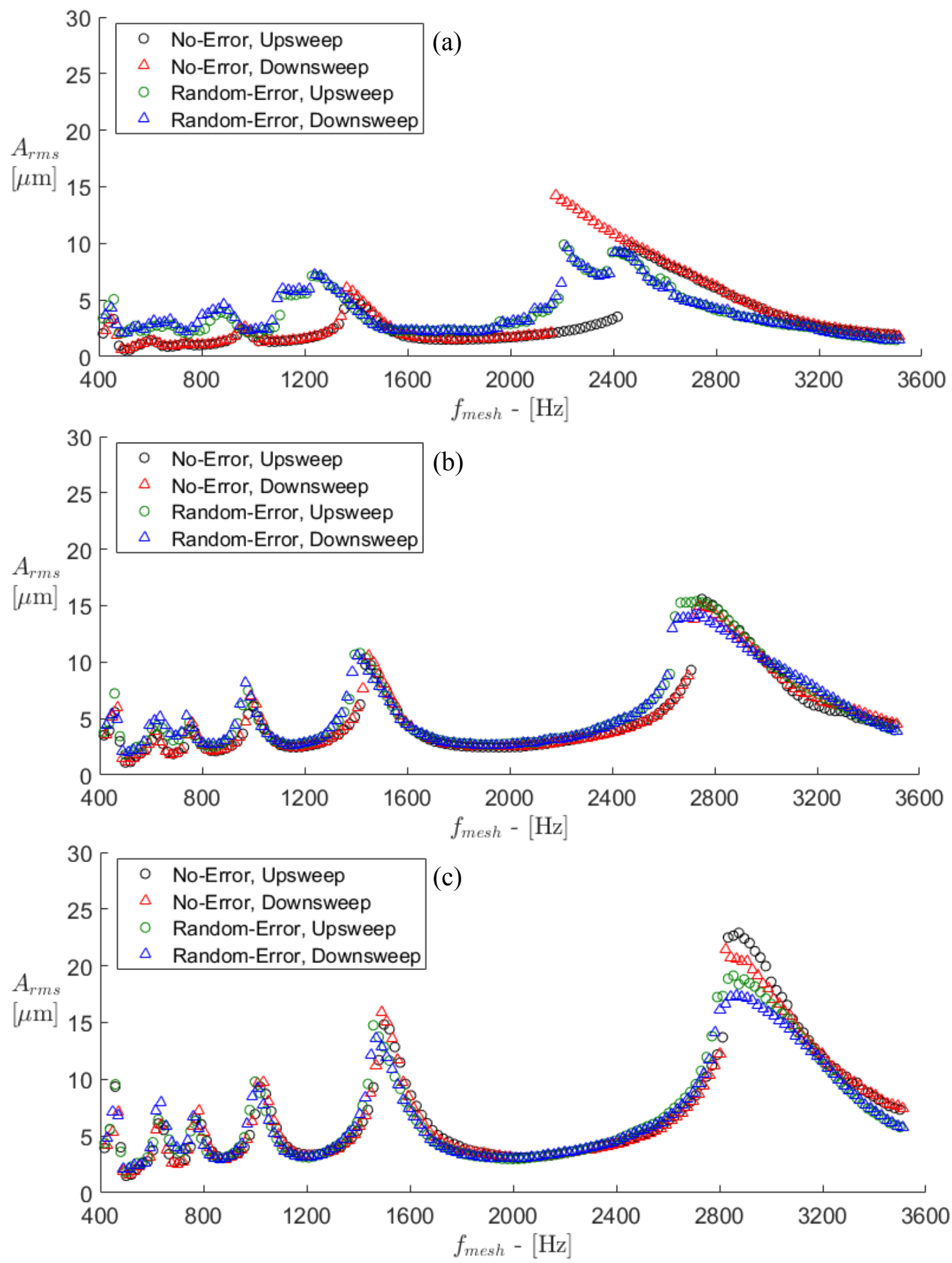

Figure 3.13: Comparison of the forces response curves (both up and down-sweep included) of the no-error and random-error gear pairs at (a) $100 \mathrm{Nm}$, (b) $200 \mathrm{Nm}$ and (c) $300 \mathrm{Nm}$. 
mesh according to Eq. (2.6). This indeed gives the impression that random errors have limited impact on the resultant dynamic behavior.

Steady-state time histories and the corresponding FFT spectrum, however, provide further information on the influence of spacing errors. Figures 3.14 to 3.19 depict these steady-state responses at $100 \mathrm{Nm}$ and $f_{\text {mesh }}=1021,1271,1667,2146,2229$, and 2438 $\mathrm{Hz}$, respectively, which correspond to rotational speeds of $\Omega=1225,1525,2000$, 2575, 2675, and $2925 \mathrm{rpm}$. The below describe observations made from these figures:

- While the periodicity of the signals over the shaft rotational period (that is, time histories for mesh segments 1-20 and 51-70) are still identical, periodicity of the signal in mesh is no longer there. While the DTE signals still maintain mesh frequency fluctuations, amplitudes for each mesh period are different because each gear tooth is now subject to a different spacing error amplitude. Because of this, the time histories look non-periodic with the corresponding phase-plane plot showing no signs of mesh frequency periodicity with a wider area covered.

- The FFT spectra of $\delta(t)$ shows that there is significant non-negligible shaftharmonic amplitudes in addition to the gear mesh harmonic amplitudes. The spectra is no longer a pure-tone spectra, but rather a broad-band spectra exhibiting sizable harmonic orders near the natural frequency as well as additional sizable orders at low-frequency ranges (say, up to 20 shaft orders). Attempting to quantify such spectra using a RMS DTE amplitude that includes only the gear mesh harmonics, as it was done in Figures 3.11 and 3.12, cannot capture the heavy non- 

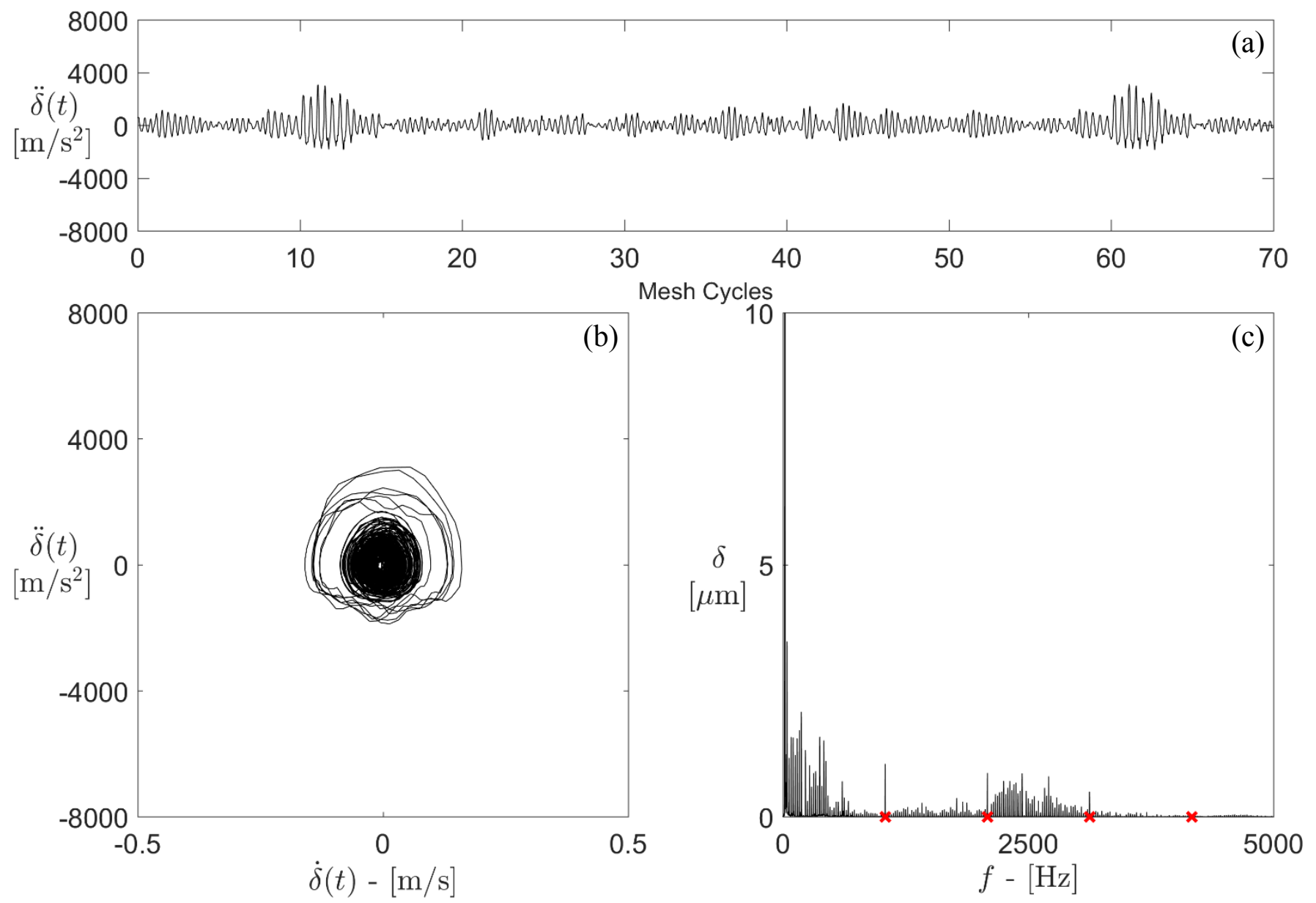

Figure 3.14: (a) $\ddot{\delta}(t)$ versus mesh cycles, (b) $\ddot{\delta}(t)$ versus $\dot{\delta}(t)$, and (c) FFT spectrum of the random-error spur gear pair at 100 Nm, $f_{\text {mesh }}=1021 \mathrm{~Hz}$ (up-sweep) in between the first and second super-harmonic peak. 

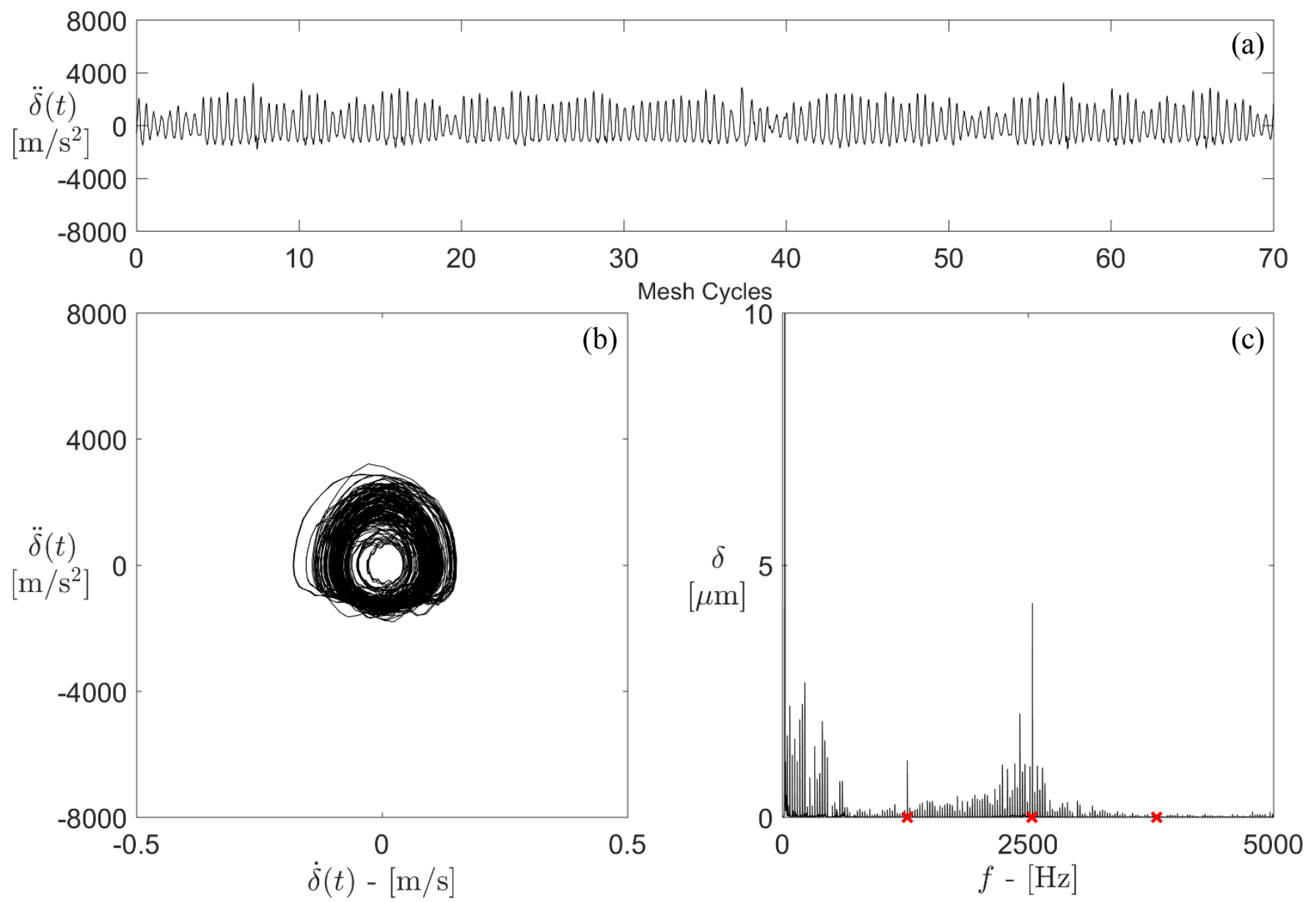

Figure 3.15: (a) $\ddot{\delta}(t)$ versus mesh cycles, (b) $\ddot{\delta}(t)$ versus $\dot{\delta}(t)$, and (c) FFT spectrum of the random-error spur gear pair at 100 Nm, $f_{\text {mesh }}=1271 \mathrm{~Hz}$ (up-sweep) at the first super-harmonic peak. 

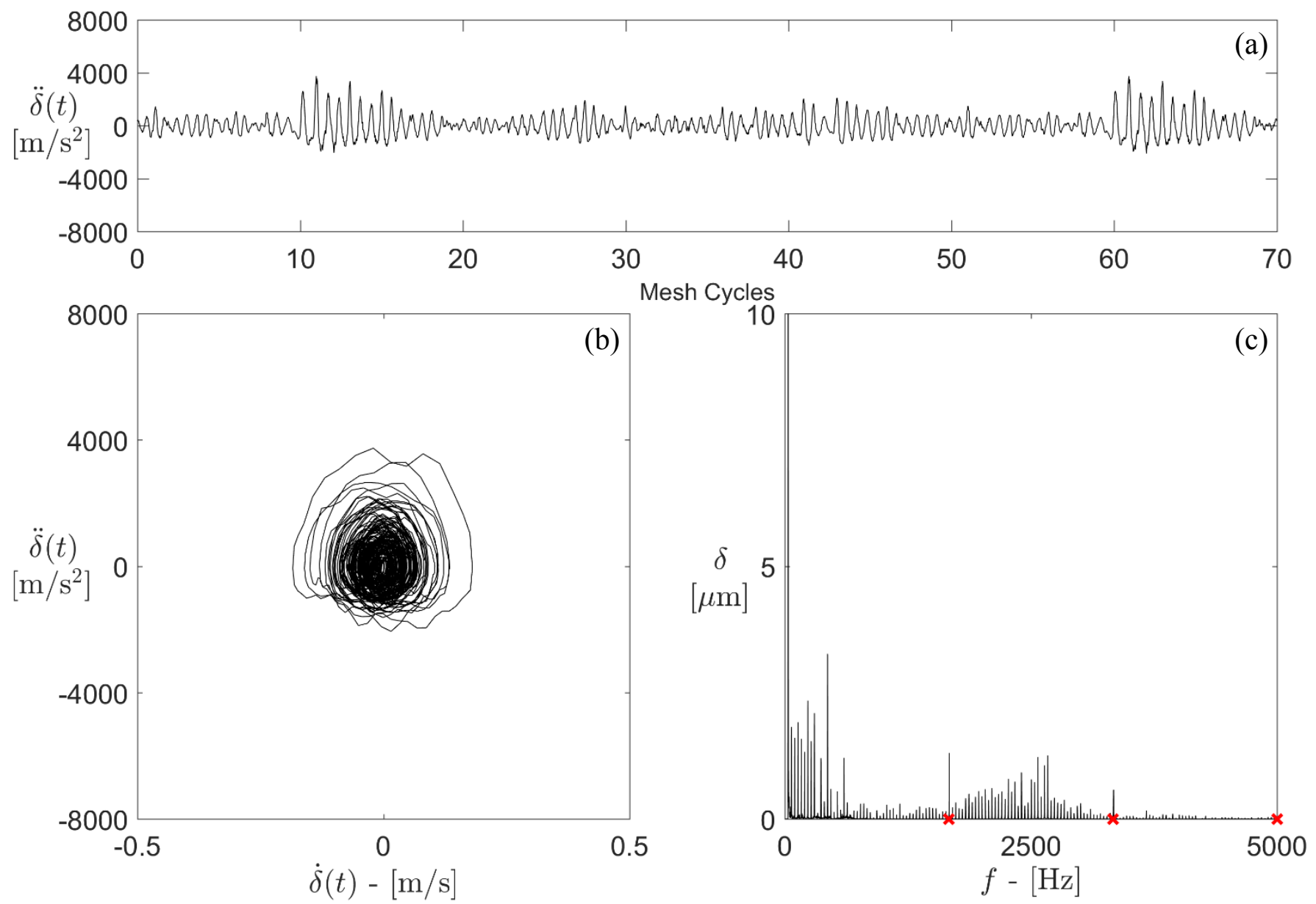

Figure 3.16: (a) $\ddot{\delta}(t)$ versus mesh cycles, (b) $\ddot{\delta}(t)$ versus $\dot{\delta}(t)$, and (c) FFT spectrum of the random-error spur gear pair at 100 Nm, $f_{\text {mesh }}=1667 \mathrm{~Hz}$ (up-sweep) between the first super-harmonic and primary resonance peak. 

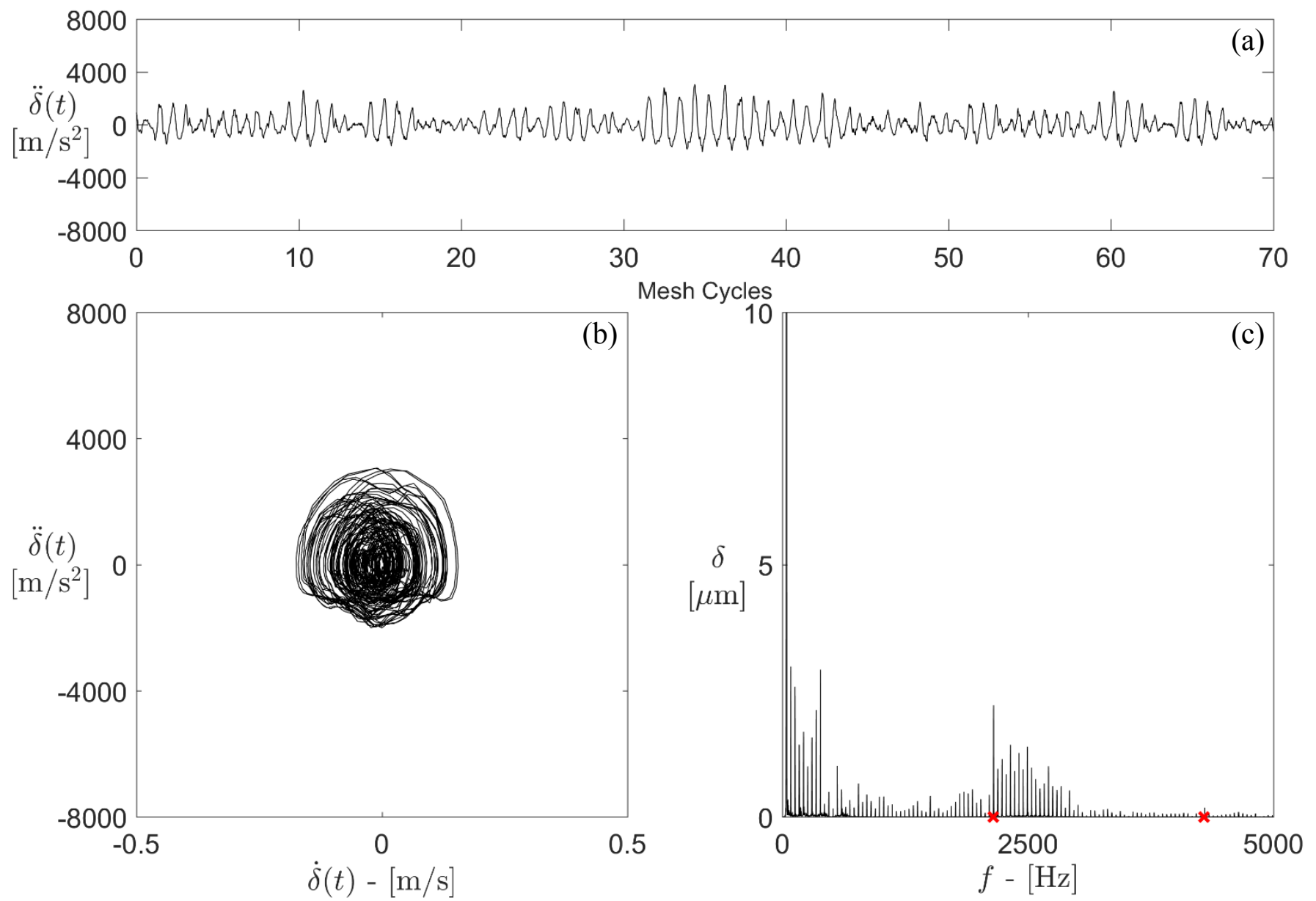

Figure 3.17: (a) $\ddot{\delta}(t)$ versus mesh cycles, (b) $\ddot{\delta}(t)$ versus $\dot{\delta}(t)$, and (c) FFT spectrum of the random-error spur gear pair at 100 Nm, $f_{\text {mesh }}=2146 \mathrm{~Hz}$ (up-sweep) prior to the first jump near resonance. 

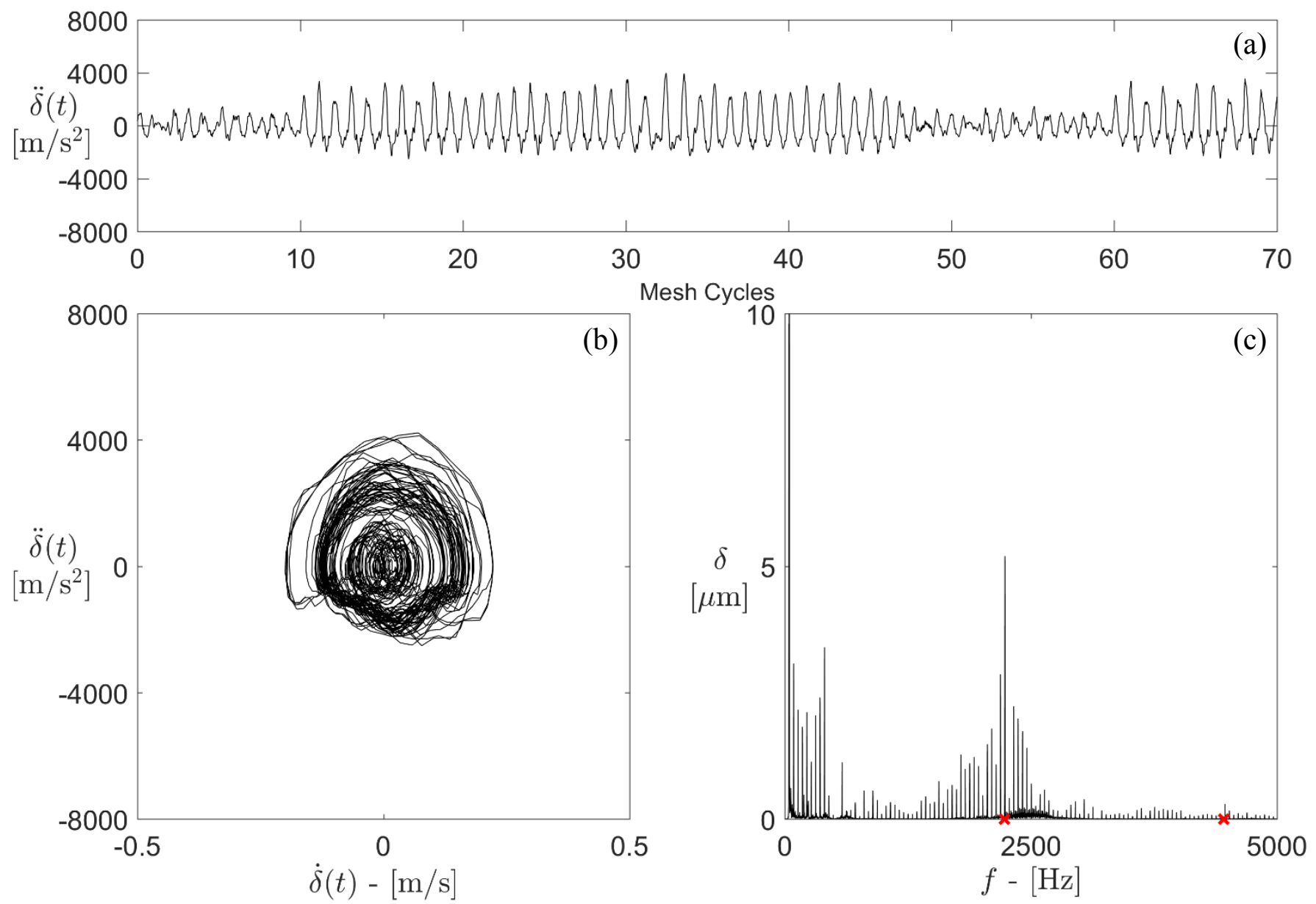

Figure 3.18: (a) $\ddot{\delta}(t)$ versus mesh cycles, (b) $\ddot{\delta}(t)$ versus $\dot{\delta}(t)$, and (c) FFT spectrum of the random-error spur gear pair at 100 Nm, $f_{m e s h}=2229 \mathrm{~Hz}$ (up-sweep) directly after the first jump approaching resonance. 

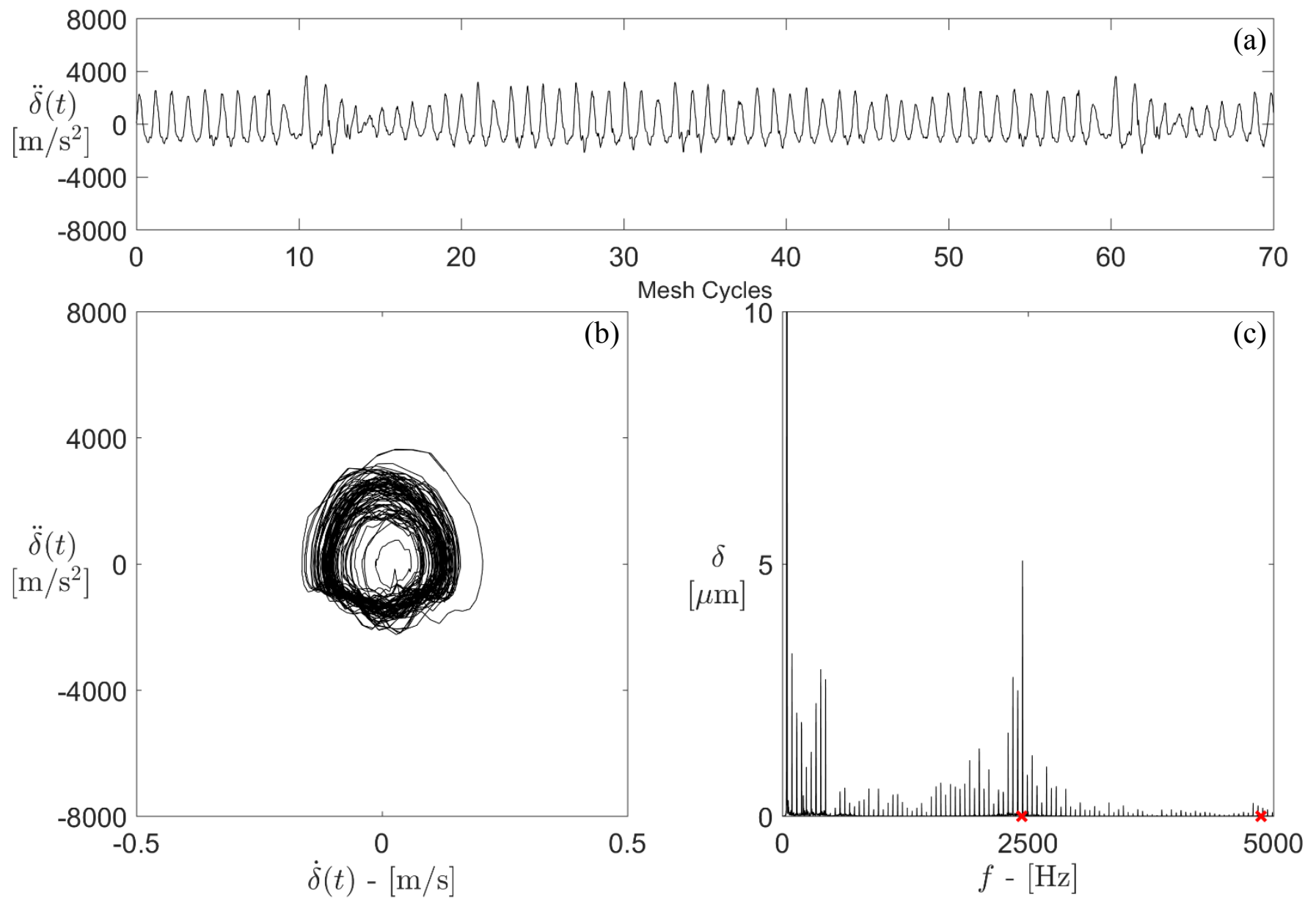

Figure 3.19: (a) $\ddot{\delta}(t)$ versus mesh cycles, (b) $\ddot{\delta}(t)$ versus $\dot{\delta}(t)$, and (c) FFT spectrum of the random-error spur gear pair at 100 Nm, $f_{\text {mesh }}=2438 \mathrm{~Hz}$ (up-sweep) after the second jump, closest to resonance. 
mesh harmonic behavior. This is why the comparisons of the forced responses of two gear pairs in Figure 3.13 do not point to significant differences.

Waterfall plots for the transient tests performed on the random-error gear set are shown in Figures 3.20 and 3.21 for torque levels of 100 and $300 \mathrm{Nm}$, respectively, both at the down-sweep condition. Distinct diagonals of $\delta(t)$ amplitudes, depicted in yellow peaks, are still present in the gear mesh orders, but significant dynamic behavior in the form of $\delta(t)$ amplitudes are present outside of the gear mesh orders throughout the whole operating range, which are the shaft harmonic frequencies, further enforcing the observation that the resulting frequency spectra are indeed broad band. 


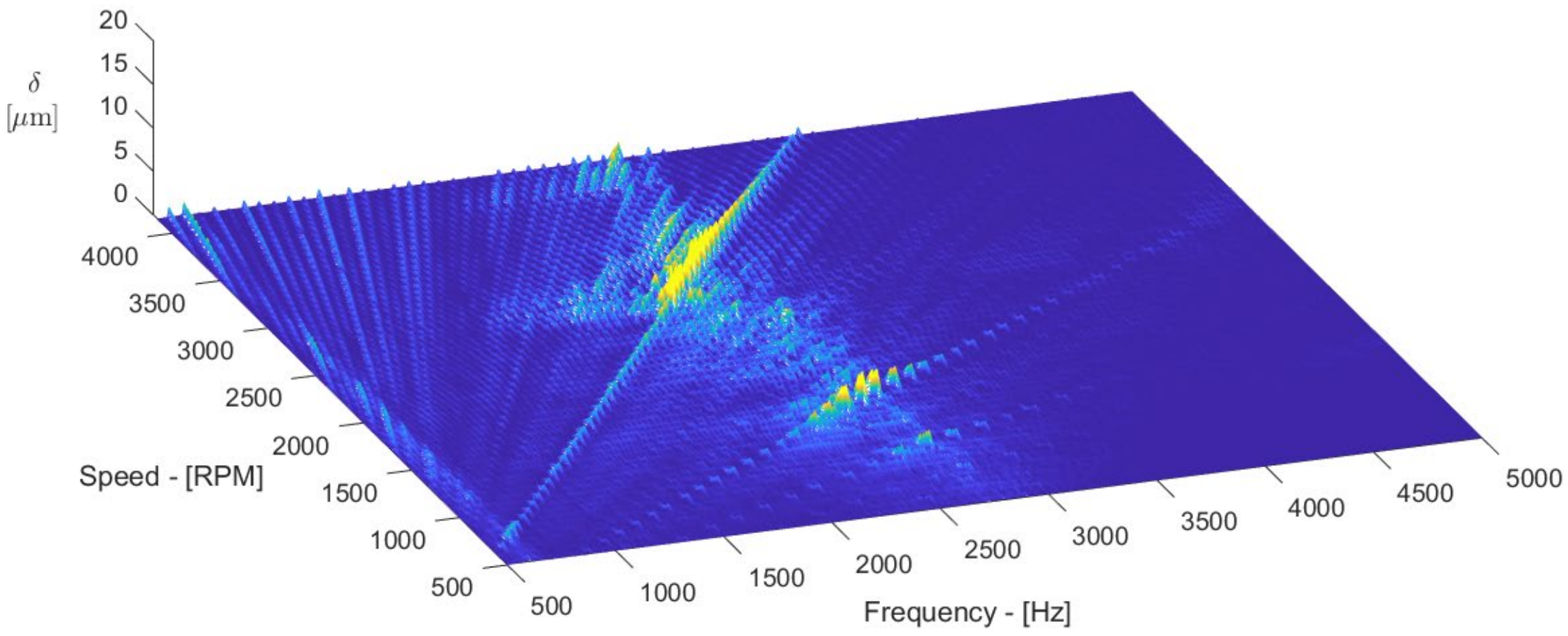

Figure 3.20: Waterfall plot of $\delta(t)$ for the random-error spur gear pair at $100 \mathrm{Nm}$ in the down-sweep condition. 


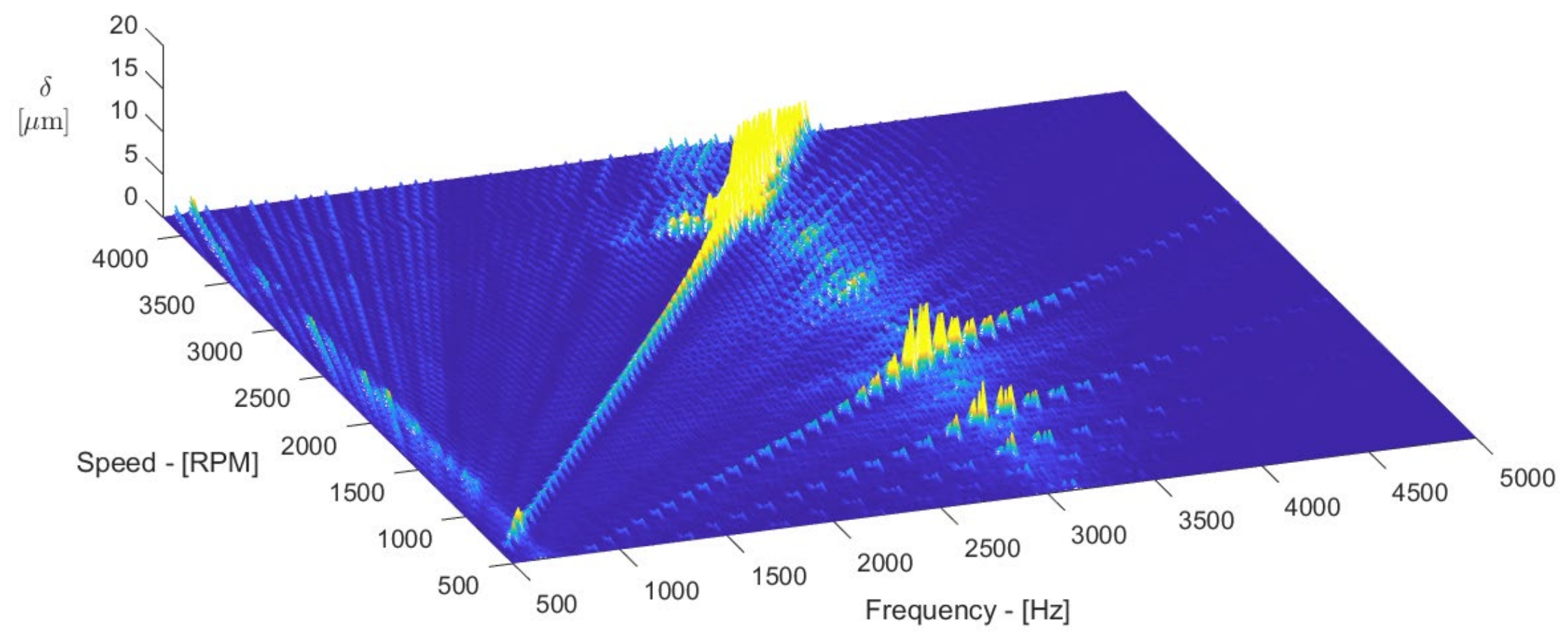

Figure 3.21: Waterfall plot of $\delta(t)$ for the random-error spur gear pair at $300 \mathrm{Nm}$ in the down-sweep condition. 


\section{CHAPTER 4}

\section{CONCLUSION}

\subsection{Summary}

This work builds on a series of research projects aiming at providing relevant insight into the effects of spacing errors on gear behavior. It is an extension to Anichowski et al. [26] who investigated the impact of isolated indexing errors (one to five consecutive teeth with spacing errors) on the dynamic transmission error of a spur gear pair. This study investigated the effect of randomly sequenced, realistic manufacturing spacing errors on the dynamic response of a spur gear pair.

Two spur gear pairs were considered in this study, one with negligibly small magnitudes of spacing errors (called the "no-error" baseline pair) and another with a random sequence of spacing errors. Each gear pair was put through the same tests under both steady-state and transient conditions within a certain range of torque. Their vibratory behaviors were compared to assess the impact of spacing errors. 


\subsection{Major Conclusions}

Based on the measurements presented in Chapter 3, the following major conclusions can be made:

- There is a clear and significant impact of random spacing errors on spur gear dynamics, measureable through examination of their respective transmission error signatures.

- In off-resonance regions of speed, DTE amplitudes can be up to 50 percent larger for the case with randomly sequenced spacing errors compared to that of the noerror baseline spur gear pair. Meanwhile, at or near resonance peaks, the presence of random spacing errors tends to lower the peak amplitudes slightly as compared to the no-error baseline spur gear pair.

- The presence of random spacing errors introduces substantial harmonic content that are non-mesh harmonics. This results in a broadband frequency spectrum to an otherwise well-defined frequency spectrum with gear-mesh order components. This points to a concern for noise quality.

- At lower torque values, for the case of the randomly sequenced gear set with errors at $100 \mathrm{Nm}$, the non-linear behavior in the form of tooth contact loss at the primary resonance peak seen in the no-error baseline test is diminished. This points to the presence of the random spacing errors bringing instability to the gear pair. 


\subsection{Recommendations for Future Work}

As an extensive database on the effect of manufacturing spacing errors has been established, this work along with other related works acts as a stepping-stone to explore the effects of various other manufacturing errors on other gear types. Many of the measurement systems and methodologies used in this study can be employed or adapted in studies investigating the effect of various manufacturing errors on various gear dynamics. As a great majority of the parallel-axis gears used in industry are not spur gears, it logically leads to the direction of studying the impact of these manufacturing errors on more commonly used gears, such as helical gears. Some potential topics for future work include:

- Experimental studies on the impact of spacing errors (of various sequences) on the response of helical gears, which have higher contact ratios. Investigations at both quasi-static operating conditions at low speeds and dynamic operating conditions at high speeds should be explored.

- Experimental studies of other types of manufacturing errors (wobble, run-out, eccentricities, etc.) on helical gear sets.

- Comparisons of the measurements from this study to dynamic load distribution simulations. 


\section{REFERENCES}

[1] Walker, H., "Gear Tooth Deflection and Profile Modification," Engineer, October 410-435, 1938.

[2] Harris, S. L., "Dynamic Loads on the Teeth of Spur Gears," Proceedings of the Institution of Mechanical Engineers, 36(428), 34-37, 1958.

[3] Welbourn, D. B., "Fundamental Knowledge of Gear Noise - A Survey," Noise Vib. Engines Transm., 9-14, 1979

[4] Mark, W.D, “Analysis of the Vibratory Excitation of Gear Systems. II: Tooth Error Representations, Approximations, and Application," Journal of Acoustical Society of America, 66(6), 1758-1787, 1979.

[5] Kohler H., Regan, R., "The Derivation of Gear Transmission Error from Pitch Error Records," Proceedings Institution of Mechanical Engineers, 199(C3), 195-201, 1985.

[6] Munro, R.G., "Effect of Geometrical Errors on the Transmission of Motion between Gears,” Proceedings Institution of Mechanical Engineers, 184, 79-84, 1969.

[7] Munro, R. G., "A Review of the Theory and Measurement of Gear Transmission Error," in Int. Conference on Gear Noise and Vibration, Institute of Mechanical Engineers, 2, 1990.

[8] Smith, J.D., "Gear Transmission Error Accuracy with Small Rotary Encoders," Proceedings of the Institution of Mechanical Engineers, 201(C2), 134-135, 1987. 
[9] Kurokawa, S., "High Precision Measurement and Analysis of Transmission Errors of Gears Under Load" in 4th World Congress on Gearing and Power Transmission, Paris, France, 1-11, 1999.

[10] Milliren, M., “An Experimental Investigation into the Influence of Various Errors on the Transmission Error and Root Stresses of Spur Gears" M.S. Thesis, The Ohio State University, Columbus, OH, 2011

[11] Handschuh, M. J., Kahraman, A., Milliren, M. R.'Impact of Tooth Spacing Errors on Root Stresses of Spur Gear Pairs,” J. Mech. Des., 136, 061010, 2014.

[12] Blankenship, G. W., Houser, D. R., "Methods for Measuring Gear Transmission Error Under Load and at Operating Speeds," SAE Tech. Paper, 1989.

[13] Kahraman, A., Blankenship, G. W., "Effect of Involute Contact Ratio on Spur Gear Dynamics," J. Mech. Des., 121, 112-118, 1999.

[14] Kahraman, A, Blankenship, G. W., "Effect of Involute Tip Relief on Dynamic Response of Spur Gear Pairs," J. Mech. Des., 121, 313-315, 1999.

[15] Kang, M. R., Kahraman, A., "Measurement of Vibratory Motions of Gears Supported by Compliant Shafts", Mechanical Systems and Signal Processing, 29, 391-403, 2012.

[16] Seireg, A., Houser, D. R., "Evaluation of Dynamic Factors for Spur and Helical Gears," J. Eng. Ind., 92, 504-514, 1970. 
[17] Houser, D. R., Seireg, A., “An Experimental Investigation of Dynamic Factors in Spur and Helical Gears," ASME J. Manuf. Sci. Eng., 92, 495-503, 1970

[18] Utagawa, M., Harada, T., "Dynamic loads on spur gear teeth having pitch errors at high speed.” Bulletin of the JSME, 18, 374, 1961.

[19] Kubo, A., Yamada, K., Aida, T.,Sato, S., "Research on Ultra High Speed Gear Devices (Reports 1-3)," Trans. JSME., 38, 2692-2715, 1972.

[20] Hayashi, T., Hayashi, I., "The Rotational Vibration of a Spur Gear with a Tooth Profile Error," Bulletin of Research Laboratory of Precision Machinery and Electronics, No. 38, 35-42, 1976.

[21] Umezawa, K., Sato, T., Kohno, K., "Influence of Gear Errors on Rotational Vibration of Power Transmission Spur Gears: 1st Report, Pressure Angle Error and Normal Pitch Error," Bulletin of the JSME, 27(225), 569-575, 1984.

[22] Umezawa, K., Sato, T., "Influence of Gear Errors on Rotational Vibration of Power Transmission Spur Gears: 3rd Report, Accumulative Pitch Error," Bulletin of the Japan Society of Mechanical Engineers, 28(246), 3018-3024, 1984.

[23] Bonori, G., Pellicano, F., "Non-smooth Dynamics of Spur Gears with Manufacturing Errors,” Journal of Sound and Vibration, 306, 271-283, 2007.

[24] Talbot, D, Sun, A. Kahraman, A., "Impact of Tooth Indexing Errors on Dynamic Factors of Spur Gears: Experimentals and Model Simulation," J. Mech. Des., 138, $093302,2016$. 
[25] Anichowski, B., "An Experimental Investigation of Spacing Errors on the Loaded Transmission Error on Spur Gears," M. S. Thesis, The Ohio State University, Columbus, OH., 2017.

[26] Anichowski, B., Talbot, D., Kahraman, A., "Dynamic Transmission Error Measurements from Spur gear Pairs having Tooth Indexing Errors," ASME Power Transmission Gearing Conference, August 6-9, Cleveland, OH, 2017.

[27] Kahraman, A., Blankenship, G.W., "Experiments On Non-Linear Dynamic Behavior of an Oscillator With Clearance and Periodically Time-Varying Parameters,” J. Appl. Mech., 64, 217-226, 1997.

[28] Blankenship, G.W., Kahraman, A., "Steady State Forced Response of a Mechanical Oscillator with Combined Parametric Excitation and Clearance Type NonLinearity,” J. Sound Vib., 185, 743-765, 1995.

[29] Kahraman, A., Blankenship, G.W., "Interactions Between Commensurate Parametric and Forcing Excitations in a System with Clearance," J. Sound Vib., 194, 317-336, 1996.

[30] Kubur, M., Kahraman, A., Zini, D., Kienzle, K. "Dynamic Analysis of a Multi-shaft Helical Gear Transmission by Finite Elements: Model and Experiment," J. Vib. Acoust., 126, 398-406, 2004.

[31] Heskamp, M., "Development of a Digital Data Acquisition and Analysis System for the Measurement of Dynamic Transmission Error of Spur and Helical Gear Pairs,” M.S. Thesis, The Ohio State University, Columbus, OH., 2007. 